\title{
A Simplified Model for Analysis of Unreinforced Masonry Shear Walls under Combined Axial, Shear and Flexural Loading
}

Bahman Ghiassi ${ }^{1,2}$, Masoud Soltani ${ }^{1, *}$, Abbas Ali Tasnimi ${ }^{1}$

${ }^{1}$ Faculty of Civil and Environmental Engineering, Tarbiat Modares University, Jalaale-al Ahmad Ave., Tehran, Iran, P.O. Box: 14115-143

${ }^{2}$ Current address: ISISE, Department of Civil Engineering, University of Minho, Guimaraes, Portugal, 4800-058

* Corresponding author: Fax: +98 21 82883381, Email: msoltani@modares.ac.ir

\section{ABSTRACT}

A macro computational model is presented in this study for simulating the nonlinear static behavior of masonry walls. The adopted strategy is based on modeling the nonlinear behavior of masonry elements considering it as an orthotropic material and then extending it with a simple method to masonry walls. The model is capable of considering shear and flexural deformations in the global behavior. It can also predict all possible failure modes in masonry such as compressive crushing, bed-joint sliding, rocking, diagonal tension cracking and diagonal stepped cracking. Suitable material constitutive models and failure criteria are adopted for each failure mode under biaxial stress states. The contact density model has been modified and used for simulating the shear behavior in the masonry joints. It is shown that the analysis results are in good agreement with experimental observations, while the analysis time is significantly lower comparing to the usual numerical approaches such as finite element methods. Moreover, the proposed model can be used as a macro-model for analysis of large structures and provides reasonable accuracy.

KEYWORDS: Masonry wall, Masonry element, Nonlinear analysis, P-M-V interaction

\section{Introduction}

Unreinforced masonry structures are widely used and constructed throughout the world. These structures were mostly vulnerable to the past earthquakes. However, in cases that they 
are designed accurately, acceptable nonlinear behavior and seismic resistance were observed from them. Therefore, an accurate prediction of the unreinforced masonry nonlinear behavior is necessary for investigating its seismic performance in design procedures.

Masonry is a composite material, consisting of brick and mortar, which makes its behavior difficult to be predicted. This difficulty is due to the different probable failure modes, complex material constitutive models, and non-uniformities in construction quality. In this regard, two main approaches known as micro-modeling and macro-modeling are usually used for simulating the nonlinear behavior of masonry structures. Micro-modeling includes the representation of bricks, mortar, and brick/mortar interfaces and is used in detailed or simplified form [1]. This modeling approach requires performing several experimental tests for calibration of material parameters. Moreover, a large number of elements should be used even for small structures. However, micro-modeling studies are necessary to give a better understanding about the local behavior of masonry structures [2]. The early efforts for micromodeling started by Page [3] and it has been continued by other authors adopting different techniques and assumptions, e.g. [4-7]. In macro-modeling, there is no distinction between brick, mortar and brick/mortar interface and masonry is modeled as a continuum anisotropic or orthotropic material. Average stresses in the continuum masonry are related to the average strains in this modeling approach. This modeling approach is simple to use and applicable to study the behavior of large elements and fewer experimental tests are needed for calibration of the material properties (e.g. [8-11]).

Despite the adopted modeling approach, a suitable predictive model should be able to capture all the possible failure modes in masonry such as tensile cracking, shear sliding, and diagonal tension cracking $[1,3,12,13]$, see Fig. 1. Moreover, adopting a general failure criterion for biaxial stress states is of crucial importance and has been the subject of many studies, see e.g. $[8,10,13-19]$. A practical method in this field is extending the isotropic constitutive laws to 
orthotropic behavior. In this approach, usually different failure criteria are used for tensile, compressive and shear behavior, see e.g. $[9,20]$.

This study presents a macro-modeling computational framework for nonlinear analysis of masonry walls under combined in-plane loads. The adopted strategy is based on modeling the behavior of masonry elements and extending it to the wall behavior following a simple method. Masonry element is the basic component of masonry members such as masonry walls, beams, and columns. Therefore, understanding the nonlinear behavior of masonry element is an important step in predicting the response of masonry members.

The model is capable of considering shear and flexural deformations in the global behavior and can predict all possible failure modes in masonry such as compressive crushing, bed-joint sliding, rocking, diagonal tension cracking and diagonal stepped cracking. Smeared crack approach is used for modeling the post-cracking behavior, considering masonry as an orthotropic homogenous material and taking into account all stress transfer mechanisms in average state. The possible failure modes have been considered in the analysis by adopting suitable material constitutive models and failure criteria in biaxial stress states. Also the nonlinear shear behavior in the joints due to the bed-joint sliding or diagonal stepped cracking has been modeled by modifying the contact density model.

The masonry element analysis framework has been combined with a flexural analysis procedure to predict the nonlinear behavior of masonry walls under combined in-plane actions. Following this approach, the model is able to consider all possible failure modes, predict the post cracking behavior of masonry, and their effects in global response of masonry walls. While the analysis time is significantly short in comparison with other micro or macromodeling approaches, the results have a good agreement with experimental observations.

\section{Material models}

Figure 1

\subsection{Masonry in biaxial compression}


Based on the experimental observations, Naraine and Sinha [21] proposed a constitutive model for unreinforced masonry panels subjected to uniaxial or biaxial compression as:

$\frac{\sigma}{\sigma_{c}}=\left(\frac{\varepsilon}{\varepsilon_{c}}\right) \exp \left(1-\frac{\varepsilon}{\varepsilon_{c}}\right)$

where $\sigma_{c}$ is the masonry compressive strength, $\varepsilon_{c}$ is the strain correspondent to $\sigma_{c}$, and $\varepsilon$ and $\sigma$ are the strain and stress in the current analysis step, respectively. This uniaxial constitutive model can be used in a biaxial stress state by using an equivalent strain concept, which was first proposed by Darwin and Pecknold [22] for concrete. In this method, the biaxial constitutive model is expressed from uniaxial curves by using equivalent strains as follows [9], see Fig. 2:

$\frac{\sigma_{i}}{\sigma_{i c}}=\left(\frac{\varepsilon_{i u}}{\varepsilon_{i c}}\right) \exp \left(1-\frac{\varepsilon_{i u}}{\varepsilon_{i c}}\right)$

where $\sigma_{i}$ is the principle compressive stress in the $i$ direction, $\varepsilon_{i u}$ is the equivalent strain in the $i$ direction, $\sigma_{i c}$ is the peak stress value in the $i$ direction, and $\varepsilon_{i c}$ is the strain corresponding to $\sigma_{i c}$. The value of $\sigma_{i c}$ should be calculated from the adopted failure criterion. Parameters $i$ and $j$ are correspondent for two principle stress directions. The equivalent strain can be calculated as follows:

$$
\varepsilon_{i u}=\frac{\varepsilon_{i}}{1-v \frac{\sigma_{j}}{\sigma_{i}}}
$$

where, $\varepsilon_{i u}$ is the equivalent strain in the $i$ direction, $\varepsilon_{i}$ is the principle strain in the $i$ direction, $\sigma_{i}$ and $\sigma_{j}$ are the principle stresses in the $i$ and $j$ directions respectively and $v$ is the Poisson's ratio. As the applicability of this model for masonry walls has been shown by Zhuge et al. [9], it is used in this study for biaxial compressive behavior.

Figure 2 
The compressive strength of masonry varies in different directions of load application which can be considered in the adopted failure criterion, see e.g. [10]. As a comprehensive example, Lourenço et al. [10] proposed a Hill-type failure criterion for masonry under biaxial stresses as follows:

$$
f_{2}=A \sigma_{x}^{2}+B \sigma_{x} \sigma_{y}+C \sigma_{y}^{2}+D \tau_{x y}^{2}-1=0
$$

where $A, B, C$, and $D$ are four material parameters such that $B^{2}-4 A C<0, A=1 / f_{m x}^{2}$, $B=\beta /\left(f_{m x} f_{m y}\right), C=1 / f_{m y}^{2}, D=\gamma /\left(f_{m x} f_{m y}\right) \cdot f_{m x}$ and $f_{m y}$ are uniaxial compressive strengths along the material axes $\mathrm{x}$ and $\mathrm{y}, \sigma_{x}$ is the applied stress in the $\mathrm{x}$ direction, $\sigma_{y}$ is the applied stress in the y direction, and $\tau_{x y}$ is the applied shear stress. The parameter $\beta$ controls the coupling between the normal stress values and for typical masonry is equal to 1 . The parameter $\gamma$ controls the shear stress contribution to failure. The variation of the masonry compressive strength with variation of the load direction, in this failure criterion, can be obtained by assuming $\sigma_{y}=0$ and calculating $f_{m}$ for different values of $\sigma_{x}$ and $\tau_{x y}$ in Eq. 4. As an example, this variation is shown in Fig. 3 for $\beta=-1$ and two different values of $\gamma$. In another study, Ganz [23] proposed the changes in compressive strength for different ratio of $\sigma_{1} / \sigma_{2}$, see Fig. 4. This model is similar to the Lourenço et al. [10] model for high values of $\gamma$. The Ganz's proposed variation [23] is simplified and used here as it is shown in Fig. 5. In the simplified model, the uniaxial compressive strength of masonry is equal to $f_{m x}$ for the $\theta$ values between 0 and $\pi / 4$ and equal to $f_{m y}$ for the $\theta$ values between $\pi / 4$ and $\pi / 2$. Verification of the model presented in the following sections shows this simplification is acceptable. However, the original model can also be implemented in the developed program. Lang [24] used also a similar simplification in his studies, but he assumed zero compressive strength for angle of inclinations larger than the angle of friction. However, Fig. 3 shows that for a reasonable 
value of $\gamma$, the variation of masonry compressive strength with variation of the load direction is between two curves shown in this figure, which is close to adopted model in this study.

Figure 3

Figure 4

Figure 5

\subsection{Masonry in tension}

When masonry is subjected to tensile forces, depending on its properties, the cracks may form vertically through the head joints and units or with a stepped path through head and bed-joints [1], see Fig. 6. When the cracks occur in a stepped pattern, the strength reduction due to cracking is small and the element has a ductile response. On the other hand, the tensile behavior is brittle with sudden decrease in strength when the cracks pass through the wall in a straight pattern. The behavior of masonry element in both failure modes is shown in Fig. 7.

Figure 6

Figure 7

For straight cracking behavior, an exponential post cracking softening model proposed by Okamura et al. [25], for concrete, is used. As the behavior of plain concrete is similar to unreinforced masonry, same material models can be used for modeling the tensile behavior. The nonlinear behavior has been assumed similar in different material axes with considering the changes in mechanical properties. This model expresses a relationship between average stresses and strains as (Fig. 8):

$\sigma=\varepsilon E \quad$ for $\quad \sigma \leq f_{t}$

$\sigma=f_{t} \times\left(\frac{\varepsilon_{t}}{\varepsilon}\right)^{c} \quad$ for $\quad \sigma>f_{t}$

where $\sigma$ is the average tensile stress, $f_{t}$ is the masonry tensile strength, $\varepsilon_{t}$ is the cracking strain, $\varepsilon$ is the average tensile strain, and $c$ is a stiffening parameter that defines the post cracking sharpness of the model ( 0.4 for deformed bars and 0.2 for welded wire mesh). The 
tension stiffening parameter, $c$, is size dependent in plain concrete and unreinforced masonry and can be obtained based on the fracture energy and crack band width. The crack band width is the crack length in the element in which the average softening stress-strain relation is defined and can be obtained from the element size and crack direction.

Figure 8

The variation of tensile strength of masonry with direction of loading is considered using a simple relation as:

$f_{t \theta}=f_{t x} \cos ^{2} \theta+f_{t y} \sin ^{2} \theta$

where $f_{t \theta}$ is the masonry tensile strength in $\theta$ direction, $f_{t x}$ is the tensile strength of masonry in $\mathrm{x}$ direction (parallel to horizontal mortar), $f_{t y}$ is the tensile strength of masonry in $\mathrm{y}$ direction and $\alpha$ is the angle of inclination of loading.

Diagonal stepped cracking is taken into account by using the nonlinear shear model considering the effective length of masonry panel in shear. The adopted shear model in this study is explained in the next section. An as example, Fig. 9 shows the results of two masonry panels under the same loading conditions analyzed with different material properties such that one fails due to straight diagonal tension cracking and one fails due to stepped diagonal tension cracking.

Figure 9

\subsection{Masonry under shear stress}

The contact density model developed by Li et al. [26] for concrete elements is modified and used for modeling the nonlinear behavior of masonry elements under shear stresses. When shear cracks appear in an element, nonlinear shear displacement and crack opening occur in the surface and the crack surfaces touch each other. This results in transferring the shear and normal compressive stresses among them, see Fig. 10. The crack surface roughness has a strong influence on the transferred stresses and the direction of the contact stress. 
Therefore, the crack surface should be idealized appropriately for formulizing the stress transfer mechanisms. The crack surface can be divided into finite parts called contact unit being known by its direction. Li et al. [26] proposed a contact density function for representing the area of contact units, $d A_{\theta}$, that have inclination angle between $\theta$ and $\theta+d \theta$ as:

$d A_{\theta}=A_{t} \Omega(\theta) d \theta$

where $A_{t}$ is the whole surface area per unit crack plane and $\Omega(\theta)$ is the probabilistic contact density function representing the distribution of crack surface directions. The contact density function should satisfy the following condition:

$$
\int_{-\pi / 2}^{\pi / 2} \Omega(\theta) d \theta=1
$$

According to the geometrical compatibility, the integration of the projection area of all contact units on the horizontal plane should be equal to unity:

$$
\int_{-\pi / 2}^{\pi / 2} d A_{\theta} \cos \theta d \theta=1
$$

Substituting Eq. 7 into Eq. 9 gives:

$$
A_{t}=1 /\left[\int_{-\pi / 2}^{\pi / 2} \Omega(\theta) \cos \theta d \theta\right]
$$

In order to formulate the constitutive equations, appropriate functions should be assumed for the contact density, contact stress, and effective contact area [26].

Figure 10

\subsubsection{Contact density}

Li et al. [26] used two-dimensional projection of crack planes experimentally scanned to develop a simple formulation for the contact density function. They obtained the histograms of contact unit length per length corresponding to each inclination. Based on the smoothed 
form of these histograms along different scanning lines, they proposed the contact density function as:

$\Omega(\theta)=0.5 \cos \theta$

where $\Omega(\theta)$ is the contact density function and $\theta$ is the crack surface direction. Having the contact density function, $A_{t}$ can be obtained by substituting Eq. 11 into Eq. 10 ( $\left.4 / \pi\right)$.

The shear failure in masonry elements usually starts in the mortar joints as a plane of weakness. Since mortar and concrete are similar, the contact density model [26] can be used for mortars using a suitable density function. Salehi [27] proposed a contact density function for mortars to overcome this problem, see Eq. 12. This function includes a parameter, $\alpha$, for controlling the cracked surface smoothness. Decrease in $\alpha$ results in smoothing the crack surface which represents a mortar with lower friction angle.

$\Omega(\theta)=0.18 \times(21 \times \alpha)^{0.5} \times \exp \left(-\alpha \times(\theta / \pi)^{2}\right)$

A disadvantage of this contact density function is that $\alpha$ is not related to the mortar type and it should be obtained through a parametric study. To overcome this problem, a formula is proposed in this study for obtaining $\alpha$ based on the masonry angle of friction, $\phi$ (in degree), see Eq. 13. This relation has been obtained by performing a parametric study on the nonlinear shear behavior of different elements with different values of $\alpha$, see Fig. 11. The corresponding friction angle for each value of $\alpha$ is the initial stiffness of the $\tau-\sigma$ curves. Base on these results, the following relation is proposed for obtaining $\alpha$ from mortar friction angle, see Fig. 12:

$\alpha=\frac{3000}{\phi^{2}}$

Figure 11

Figure 12

\subsubsection{Contact stress}


The stress state at the contact area is different from uniaxial compressive behavior. The mortar around the contact area would be elastically and highly plastically deformed under the confinement. Considering the high plasticity in the shear transfer behavior, the compressive stress in contact area is assumed elasto-perfectly plastic in this model (Fig. 13) which can be formulated as follows:

$\sigma_{c o n}^{\prime}=\left\{\begin{array}{l}R_{S}\left(\omega_{\theta}^{\prime}-\omega_{\theta p}^{\prime}\right) \quad \text { for } \quad \omega_{\theta}^{\prime}>\omega_{\theta p}^{\prime} \\ 0 \quad \text { for } \quad \omega_{\theta}^{\prime}<\omega_{\theta p}^{\prime}\end{array}\right.$

where $\omega_{\theta}^{\prime}$ is the compressive contact displacement, $\omega_{\theta p}^{\prime}$ is the plastic compressive contact displacement, and $R_{S}$ is the elastic rigidity per unit length. These parameters can be calculated as:

$\omega_{\theta}^{\prime}=\delta \sin \theta-\omega \cos \theta$

$\omega_{\theta p}^{\prime}=\left\{\begin{array}{l}\omega_{\text {max }}^{\prime}-\omega_{\text {lim }}^{\prime} \text { for } \omega_{\text {max }}^{\prime}>\omega_{\text {lim }}^{\prime} \\ 0 \text { for } \omega_{\max }^{\prime} \leq \omega_{\text {lim }}^{\prime}\end{array}\right.$

$R_{s}=f^{\prime}{ }_{y} / \omega^{\prime} \lim$

where $\omega_{\text {max }}^{\prime}$ is the maximum compressive contact displacement ever experienced, $\omega_{\text {lim }}^{\prime}$ is the elastic limit of compressive contact displacement equal to $0.04 \mathrm{~mm},{f^{\prime}}_{y}$ is the contact yielding strength equal to $13.7 f_{c}^{1 / 3}$ in MPa units. The values of $\omega^{\prime}{ }_{\lim }$ and $f^{\prime}{ }_{y}$ are obtained based on the curve fitting of experimental results performed on concrete specimens [26]. Maekawa et al. [28] showed that the crack configuration for mortar is similar to that in high strength concrete. Since mortar contains no coarse aggregates, the cracks are formed naturally flat similar to cracks in high-strength concrete. They also showed that other parameters including "the elastic limit of compressive contact displacement", "contact yielding strength" and "effective ratio of contact area" which originally developed for normal concrete can also be used for cracked mortar. Therefore, these values are used in this study although performing comprehensive experimental tests are required for a better verification. 
Figure 13

\subsubsection{Contact effective area}

The contact density function includes the effect of crack surface shape without considering the contact size. The contact area decreases with increase in crack width and there will be no contact if the crack width is large enough in comparison to the crack's roughness. Based on the experimental observations of crack surfaces in concrete elements, an effective ratio of contact area denoted by $K$ is defined in this model as [26]:

$K=1-\exp \left(1-0.5 G_{\max } / \omega\right)$

where $G_{\max }$ is the maximum aggregate size.

\subsubsection{Constitutive equations}

The integral of the components of the contact compressive force within an infinite small range must be balanced with shear and normal stresses transferred to the plane [26]:

$$
\sigma^{\prime}=\int_{-\frac{\pi}{2}}^{\frac{\pi}{2}} Z^{\prime} \cos \theta d \theta, \tau=\int_{-\frac{\pi}{2}}^{\frac{\pi}{2}} Z^{\prime} \sin \theta d \theta
$$

where $Z^{\prime}$ is the compressive stress acting on a contact unit which can be calculated as:

$Z^{\prime}=\sigma_{c o n}^{\prime} K A_{t} \Omega(\theta)$

where $\sigma_{c o n}^{\prime}$ is the contact compressive stress (Eq. 14) and $K$ is the effective ratio of contact (Eq. 18).

The contact density model is applicable for modeling the shear behavior after cracking. Therefore, cohesion is not considered in the cracked surfaces in this model. This assumption is accurate when the plastic deformations reach a minimum value in which the material cohesion has been vanished. The cohesion starts to decrease after initiation of cracks until it vanishes when the cracks are formed completely. The crack usually follows the weak interfaces between the aggregates and hardened cement in the mortar or concrete. Depending 
on the loading conditions and material properties two failure modes occur [29], see Fig. 14. In Mode I, both sides of the crack separate from each other in the normal direction to the crack surface. Considerable roughness may still be present in the crack surface in this failure mode. Mode II occurs when the shear displacement is applied on the crack surface while no dilatancy is allowed. This failure usually happens in the elements under high axial loads or confined elements.

\section{Figure 14}

The decrease of cohesion due to the formation cracks is considered in this study as follows:

$$
\left\{\begin{array}{l}
C=G_{m} \delta / t_{m} \quad \text { for } \delta<\delta_{m} \\
C=\tau_{m o h r} \times\left(1-\frac{\delta-\delta_{m}}{20 \delta_{m}}\right) \times\left(\frac{\delta_{m}}{\delta}\right)^{\alpha} \quad \text { for } \delta>\delta_{m}
\end{array}\right.
$$

where $C$ is the mortar cohesion coefficient, $G_{m}$ is the mortar shear modulus, $t_{m}$ is the mortar thickness, $\delta$ is the shear displacement, $\delta_{m}$ is the elastic limit of shear displacement, $\tau_{m o h r}$ is the shear strength according to Mohr-Coulomb criterion and $\alpha$ controls the rate of decrease in the cohesion ( $\alpha=1$ in this study).

This model consists of two main parts. The first part is the shear behavior until reaching the peak shear stress which is assumed linear elastic, see first relation in Eq. 21. Therefore, the elastic limit of shear displacement, $\delta_{m}$, can been obtained as follows:

$$
\delta_{m}=\frac{\tau_{m o h r}}{G_{m}} t_{m}
$$

The second part represents the softening behavior in the cohesion after shear peak stress and is proposed similar to the model proposed in [29], second relation in Eq. 21. In this equation, the term $\left(\frac{\delta_{m}}{\delta}\right)^{\alpha}$ is used to simply account for the softening behavior similar to the proposed trend in [29]. The term $\left(1-\frac{\delta-\delta_{m}}{20 \delta_{m}}\right)$ is an interpolation between the elastic limit of shear displacement, $\delta_{m}$, and the shear displacement in which the cohesion vanishes completely. The 
shear displacement corresponding to complete disappearance of cohesion is assumed equal to $20 \delta_{m}$ in this study. However, performing an extensive investigation and obtaining the shear fracture energy of masonry are necessary for verification of this value.

The total shear behavior of masonry element is the summation of the two discussed phenomena, see Fig. 15.

Figure 15

To control the accuracy of the proposed model, one of the tests conducted by Atkinson et al. [30] is selected here. These tests consist of direct shear tests on old and new masonry bedjoints. The mortar properties and loading condition of the selceted specimen are shown in Table 1. The reasonable agreement found between the analysis and experimental results can be observed in Fig. 16.

\section{Table 1}

\section{Figure 16}

\section{Failure criteria}

Proposing a general failure criterion for masonry has been the subject of many studies for many years [13-19]. An accurate analysis of masonry structures in a macro-modeling approach, requires a comprehensive failure criterion able to predict all the possible failure modes in biaxial stress state. However, a combination of different failure criteria can be also used. Depending on the stresses state acting on the joints, the failure occur in the joints or in a combination of brick and mortar.

Naraine and Sinha [21] conducted experimental tests on masonry panels and found the following failure criterion has the best fit to the experimental data:

$$
C J_{2}+(1-C) I_{1}+C I_{2}=1
$$

where $J_{2}, I_{1}$, and $I_{2}$ are principal stress invariants defined as: 
$J_{2}=\left(\frac{\sigma_{1}}{f_{m 1}}-\frac{\sigma_{2}}{f_{m 2}}\right)^{2}$

$I_{1}=\left(\frac{\sigma_{1}}{f_{m 1}}+\frac{\sigma_{2}}{f_{m 2}}\right)$

$I_{2}=\left(\frac{\sigma_{1}}{f_{m 1}} \times \frac{\sigma_{2}}{f_{m 2}}\right)$

where $\sigma_{1}, \sigma_{2}$ are principle compressive stresses, $f_{m 1}, f_{m 2}$ are average uniaxial compressive strengths in the direction of principle stresses, and $C$ is a constant that controls the failure interaction curve and is equal to 1.6 in this study as is porposed by Naraine and Sinha [21]. Using a value of 1 for this parameter reduces this failure criterion to Von Mises yeild criterion. This failure criterion is used in this study for biaxial compressive failure of masonry elements.

To control the shear failure in masonry joints, the Coulomb failure criterion is used:

$$
\begin{aligned}
& \tau_{x y}=\tau_{x y}{ }^{m} \\
& \tau_{x y}{ }^{m}=\tau_{\circ}+\mu \sigma_{y}
\end{aligned}
$$

where $\tau_{x y}$ is the applied shear stress, $\tau_{\circ}$ is the shear bond strength (masonry cohesion), $\mu$ is friction coefficient of the brick mortar interface, and $\sigma_{y}$ is the applied stress normal to bedjoints.

For tension-compression range, the failure criterion developed at the University of Tokyo [31] for concrete is used. In this failure criterion the tensile strength can be obtained as:

$$
\sigma_{2}=f_{t 2} \sqrt[3]{1-\frac{\sigma_{1}}{f_{m 1}}}
$$

where $f_{t 2}$ is the uniaxial tensile strength in the direction of investigation. The element cracking under tensile stresses results in decrement of compressive strength in the transverse direction. Niwa et al. [31] proposed Eq. 30 to consider this reduction in RC elements, see Fig. 17. Due to the lack of experimental data, the same relation is used in this study. 


$$
\begin{aligned}
f^{\prime}{ }_{m} & =R_{d} \times f_{m} \\
R_{d} & =\frac{1}{0.8-0.34 \frac{\varepsilon_{t}}{\varepsilon_{c \max }}} \leq 1
\end{aligned}
$$

where ${f^{\prime}}_{m}$ is the reduced compressive strength, $f_{m}$ is the uniaxial compressive strength, $\varepsilon_{t}$ is the tensile strain normal to the compressive stress, and $\varepsilon_{c \max }$ is the peak compressive strain.

The complete shape of the adopted failure critera is shown Fig. 18 in terms of principle stresses. It should be noted that the shape of the failure criteria may change by changing $\theta$ due to the changes in material properties in different material axes.

Figure 17

Figure 18

For better illustrating the adopted failure criteria, it has been transformed from the principle stresses state (Fig. 18) to stresses normal and parallel to the bed-joints, $\sigma_{y}, \tau_{x y}$, see Fig. 19. In this figure the Coulomb failure criterion which is used for assessment of shear failure is also recognizable. It can be seen that with increasing the degree of inclination of the applied stresses, $\theta$, the horizontal axis, $\sigma_{y}$, rotates towards the vertical axis, $\tau_{x y}$. Due to this rotation, the shear failure governing region increases. After 45 degrees, the shear failure will be the controlling behavior in all the stress states. This fact has been also approved in [3].

Figure 19

\section{Unreinforced masonry element analysis}

Different approaches have been used for modeling the post cracking behavior of concrete and masonry. These approaches are usually classified into two main groups called discrete and smeared crack models.

In the discrete crack models, cracking is assumed to occur as soon as the nodal force normal to the element boundaries exceeds the maximum tensile force that can be sustained. Once the 
crack is occurred, the node is separated into two nodes and the crack extends along the element which requires continuous remeshing. However, continuous remeshing can be avoided following new algorithms.

In the smeared crack models, the cracks and reinforcing bars are smeared over the element. The cracks, once generated, are not modeled directly but their effects are considered by changing the material constitutive models. The smeared crack approach can be divided into rotating and fixed crack approaches. The rotating crack model assumes that the crack direction coincides with the principal direction of average strain. Therefore, it can be changed or rotated following the stress condition. Since there is no shear stress on the continually updated principle planes, no shear model is required in this method. Therefore, this approach does not explicitly account for shear slip and shear stress transfer due to aggregate interlock. In the fixed crack approach, the crack direction does not change during the analysis until it changes more than a specific value. Therefore, shear stresses develop in the crack surface due to aggregate interlock which can be modeled by means of a suitable constitutive model. The rotating crack approach is used in this study for simulating the nonlinear behavior of unreinforced masonry elements.

The masonry element is assumed to have a uniform thickness and relatively small size, see Fig. 20. The deformations occur such that the edges remain straight and parallel and the applied in-plane stresses or strains cause in-plane strains or stresses in the element.

Figure 20

By applying in-plane incremental stresses or strains, the nonlinear behavior of the masonry element can be obtained following an iterative solution method, see Fig. 21. In each step of the analysis the shear strain increases. Assuming the strains in $\mathrm{x}$ and $\mathrm{y}$ direction, the corresponding stresses can be obtained by transferring the strains to the principle directions and using the adopted constitutive models. The obtained principle stresses can then be 
transferred to the global $\mathrm{x}$ and $\mathrm{y}$ directions. The assumed strain values in $\mathrm{x}$ and $\mathrm{y}$ direction are adjusted through an iterative solution method until satisfying the stress equilibrium conditions. The modified Newton-Raphson method is used in this study for performing the iterative procedure.

Figure 21

Most of the available experimental data on the behavior of masonry elements are focused on determining the failure surfaces and less effort has been devoted to the full range nonlinear behavior under biaxial stresses. Therefore, the accuracy of the adopted methodology is controlled through verification of the analysis results for masonry walls.

\section{Wall analytical model}

Accurate simulation of the nonlinear behavior of masonry walls requires considering the flexural and shear deformations and all the possible failure modes. Shear deformations, which are usually neglected in the simplified analysis procedures, have an important role in total nonlinear displacements in masonry walls. For this reason, the effects of flexural and shear stresses and their corresponding deformations on the global behavior of the masonry walls are considered here. Moreover, all the possible failure modes such as rocking, diagonal tension, diagonal stepped cracking, toe compression, and bed-joint sliding can be captured.

The flexural behavior is computed considering a macro fiber model and performing a moment-curvature analysis which is described later in this section. For considering the shear behavior of the wall, the following procedure is applied, see Fig. 22:

In each step of the moment-curvature analysis, the corresponding shear force and displacement (as it is described in sec. 5.1) and the wall uncracked length are calculated. Then the shear displacement of the wall corresponding to the shear force obtained in each step of the moment-curvature analysis is calculated. This shear displacement is calculated by analyzing the wall as a masonry element under in-plane stresses with the height and length 
equal to the height and uncracked length of the wall (as it is described in sec. 5.2), respectively. The total displacement of the wall is then calculated as the summation of the shear displacement calculated in the moment-curvature analysis and the shear displacement obtained in the shear analysis. In cases in which the masonry element cannot reach the shear stress obtained in the moment-curvature analysis, the shear failure becomes the governing behavior of the wall from that step. Therefore, the next steps will be followed by shear analysis.

Figure 22

\subsection{Flexural modeling}

\subsubsection{Moment-curvature analysis}

Adopted method here for flexural analysis of masonry wall resembles a macro fiber model. In this model the wall is divided into a series of uniaxial elements, see Fig. 23.

Figure 23

Considering the applied axial force on the wall, the moment-curvature analysis can be conducted by assuming a linear strain distribution across the wall cross section and calculating the stresses in each fiber using the material constitutive models, see Fig. 24 . The assumed strain distribution is adjusted in an iterative procedure until obtaining the resultant axial force equal to the applied axial force, $\mathrm{N}$ (Eq. 32 should be satisfied). This adjustment is performed by changing the strain values in the first and last fibers and assuming a linear distribution of strains between them. After obtaining the correct strain distribution in each step of the analysis, the moment and curvature in the section can be computed using Eqs. 33, 34.

Figure 24

$\sum \sigma_{i} A_{i}=N$

$\sum \sigma_{i} A_{i} y_{i}=M$ 
$\kappa=\frac{\varepsilon_{t}+\varepsilon_{c}}{l}$

where, $\sigma_{i}$ is the stress in each fiber, $A_{i}$ is the area of each fiber, $N$ is the constant axial force

applied to the wall, $y_{i}$ is the fiber distance to the neutral axis of the section, $\kappa$ is the curvature of the section, $\varepsilon_{t}$ is the first layer strain, $\varepsilon_{c}$ is the last layer strain and $l$ is the section length.

\subsubsection{Shear-displacement curve due to flexural behavior}

Using the Eq. 35, the shear force corresponding to the applied moment can be computed in each step, see Fig. 25. The curvature is also convertible to the wall base rotation, $\theta$, using Eq. 36. Then, the top displacement of the wall can be calculated from the wall base rotation, see Eq. 37.

$V=\frac{M}{h}$

$\theta=\int_{0}^{h} \frac{\kappa \cdot x}{h} d x$

$\delta=\theta \frac{l}{h}$

where $h$ is the wall height. Therefore, by computing the shear force and displacement corresponding to the applied moment and curvature in each step of the analysis, the sheardisplacement curve of the wall due to flexural behavior can be obtained.

Figure 25

\subsection{Shear behavior}

The nonlinear shear behavior of the masonry wall is modeled by assuming the wall as a masonry element (Fig. 26) with a height equal to the height and a length equal to the uncracked length of the wall. Since the cracked length of the wall is under tensile stresses and the crack surfaces are relatively smooth, the resistance of the cracked length of the wall against shear forces is negligible [24, 32-33]. The uncracked length of the wall can be 
obtained in each step of the moment-curvature analysis by reducing the length of the cracked fibers from the total length of the wall. The assumed masonry element is then analyzed under the applied normal and shear stresses following the described method in sec. 4.

\section{Figure 26}

\section{Structural verification}

The ability of the proposed method to predict the nonlinear behavior of the masonry walls is validated in this section by comparing the analytical and experimental results of the tests performed by Ganz and Thurlimann [34], Abrams and Shah [35], and Yaghoubifar [36]. The first series of the walls analyzed consists of the walls carried out by Ganz and Thurlimann [34] denoted by W1 and W2. These walls consist of hollow clay brick masonry with the geometries shown in Fig. 27. The material properties taken from Ganz and Thurlimann [34] are shown in Table 2 and Table 3. The walls are subjected to a uniform vertical load followed by an incremental horizontal load, F, to obtain the shear-displacement behavior. The initial vertical load, $P$, was equal to $415 \mathrm{KN}=0.61 \mathrm{MPa}$ for wall $\mathrm{W} 1$ and $1287 \mathrm{KN}=1.91 \mathrm{MPa}$ for Wall W2. Wall W1 showed a ductile response with tensile and shear failure along the diagonal stepped cracks. Wall W2 behavior was started by a relatively ductility followed by brittle cracking. Similar failure modes and shear-displacement curves have been obtained in the analysis, see Fig. 28. The contribution of shear and flexural deformations in the global behavior of the wall is also shown in this figure.

Figure 27

Table 2

Table 3

Figure 28

The first series of selected walls are tested by Abrams and Shah [35]. These experimental tests consist of three masonry walls with different height-to-length ratio and vertical 
compressive stresses subjected to cyclic loading pattern. The geometry, material properties, and loading conditions of the walls are shown in Fig. 29 and Table 4. In terms of material properties, $f_{m y}, c$, and $\varphi$ were given in [35], while the other parameters are used based on available information with considering the best fitting of experimental results. The observed failure modes of the walls are also presented in Table 4. Wall W1 failed in shear showing diagonal cracks with no flexural cracking. Wall W2, subjected to a lower vertical compressive force, showed flexural cracks on the bed-joints followed by diagonal cracking at the ultimate stages of the test. Wall W3 had a flexural rocking behavior.

The analysis results together with the contribution of shear and flexural deformations are shown in Fig. 30. A good agreement is found between the analytical and experimental results and the same failure modes have been predicted. It can be observed that the flexural deformations are small in wall $\mathrm{W} 1$ as it was expected from the experimental observations. The contribution of flexural deformations increases in wall W2. The analysis results show the behavior is governed by the flexural deformations at the initial stages and is followed by diagonal stepped cracking, similar to experimental observations. The analysis results for the wall W3 is also in complete agreement with the experimental results. The flexural deformations govern the behavior with contribution of small shear deformations.

Figure 29

Table 4

Figure 30

Yaghoubifar [36] studied the behavior of two unreinforced and four strengthened masonry walls by performing static-cyclic testes. The wall NSBW1 is selected here as another reference specimen for verification of the proposed analytical model. The geometry and material properties of the wall are shown in Fig. 31 and Table 5, respectively. The governing failure mode of this specimen was rocking behavior followed by sliding in the bed-joints, due 
to the low applied vertical stress and tensile strength of the bed-joint mortar. The analysis and experimental results are compared in Fig. 31 . The numerical results are in good agreement with experimental observations. The rocking behavior was observed in the simulations followed by sliding in the bed-joints as well as the experimental tests.

\section{Table 5}

Figure 31

\section{Conclusions}

A macro-modeling method is presented in this paper for predicting the nonlinear behavior of masonry walls with considering all the possible failure modes. Suitable constitutive models and biaxial failure criteria have been selected and masonry is assumed as an orthotropic material. Shear and flexural deformations, which play an important role in global response of the walls, has been considered in a simplified manner. The shear deformations are obtained by modeling the nonlinear behavior of masonry element and extending it to the masonry wall. The contact density model developed at the University of Tokyo is modified and used for modeling the shear failure in masonry elements. The presented computational framework can be used for predicting the nonlinear behavior of masonry walls with different geometries and material properties.

The accuracy of the adopted method is performed by comparing the analytical and experimental results. It is shown that the accuracy of the predicted results is acceptable while the analysis time is significantly less than finite element methods. Moreover, the contribution of shear and flexural deformations were also shown in global behavior of the reference specimens. 


\section{References}

[1] Lourenço PB. Computational strategies for masonry structures. PhD thesis. Delft University of Technology, Delft, The Netherlands; 1996.

[2] Lourenço PB. Computations on historic masonry structures. J Prog Struct Eng Mater $2002 ; 4: 301-19$

[3] Page AW. Finite element model for masonry. ASCE J Struc Div 1978; 104(8):1267-85.

[4] Lourenço PB, Rots G. A multi-surface interface model for the analysis of masonry structures. J Eng Mech 1997; 123(7):660-8.

[5] Senthivel R, Lourenço PB. Finite element modelling of deformation characteristics of historical stone masonry shear walls. Eng Struct 2009; 31(9):1930-43.

[6] Dolatshahi KM, Aref AK. Two-dimensional computational framework of meso-scale rigid and line interface elements for masonry structures. Eng Struct 2011;33(12):3657-67.

[7] Calio I, Marletta M, Panto B. A new discrete element model for the evaluation of the seismic behaviour of unreinforced masonry buildings. Eng Struct 2012; 40:327-38.

[8] Dhanaeskar M, Kleeman PW, Page AW. Biaxial stress-strain relations for brick masonry. J Struct Div 1985; 111(5):1085-110.

[9] Zhuge Y, Thambiratnam D, Corderoy J. Nonlinear dynamic analysis of unreinforced masonry. J Struct Eng 1998; 124(3):270-7.

[10] Lourenço PB, Rots G, Blaauwendraad J. Continum model for masonry: Parameter estimation and validation. J Struct Eng 1998; 124(6):642-52.

[11] Chen SY, Moon FL, Yi T. A macroelement for the nonlinear analysis of in-plane unreinforced masonry piers. Eng Struct 2009; 30(8):2242-5.

[12] Page AW. The strength of brick masonry under biaxial compression-tension. Int J Mason Cosntr 1983; 3(1):26-31. 
[13] Lishak VI, Yagust VI, Yankelevsky DZ. 2-D Orthotropic failure criteria for masonry. Eng Struct 2012; 36:360-71.

[14] Yokel FY, Fattal SG. Failure hypothesis for masonry shear walls. J Struct Div 1976; 102(3):515-32.

[15] Mann W, Muller H. Failure of shear-stressed masonry - an enlarged theory, tests and application to shear walls. Proc Brit Ceram Soc 1982;30:233-35.

[16] Pela L, Miguel C, Roca P. Continuum damage model for orthotropic materials: Application to masonry. Comput Method Apll Mech Eng 2011; 200(9-12):917-30.

[17] Milani G, Lourenço PB, Tralli A. 3D homogenized limit analysis of masonry buildings under horizontal loads. Eng Struct 2007; 29(11):3134-48.

[18] Andreaus U, Ceradini G. Failure modes of solid brick masonry under in-plane loading. Mason Inter 1992; 6(1):4-8.

[19] Andreaus U. Failure criteria for masonry panels under in-plane loading. J Struct Div ASCE 1996; 122(1):37-46.

[20] Lourenço PB, De Borst R, Rots JG. Plane stress softening plasticity model for orthotropic materials. Int J Numer Method Eng 1997; 40(21):4033-57.

[21] Naraine K, Sinha S. Cyclic behavior of brick masonry under biaxial compression. J Struct Eng 1991; 117(5):1336-55.

[22] Darwin D, Pecknold DA. Nonlinear biaxial stress-strain law for concrete. J Eng Mech Div 1977; 103(2):229-41.

[23] Ganz HR. Masonry walls subjected to normal and shear forces. Report No. 148, Inst Struct Eng, ETH Zurich; 1985 (in German).

[24] Lang K. Seismic vulnerability of existing buildings. PhD thesis. Swiss Fed Inst Technol Zurich, Zurich, Switzerland; 2002. 
[25] Okamura H, Maekawa K, Sivasubramaniyam S. Verification of modeling for reinforced concrete finite element. Proc Finite Elem Anal Reinf Conc Struct, ASCE 1985; 528-43.

[26] Li B, Maekawa K, Okamora H. Contact density model for stress transfer across cracks in concrete. J Fac Eng, Univ Tokyo 1989; 40(1):9-52.

[27] Salehi I. Determination of average stress-strain constitutive models and fracture of unreinforced masonry elements using micro-modeling and interaction of masonry components. MSc. Dissertation, Dep Civil Eng, Tarbiat Modares Univ: Tehran; 2006.

[28] Maekawa K, Pimanmas A, Okamura H. Nonlinear mechanics of reinforced concrete. Tokyo, Japan: Gihodo-Shuppan; 1990.

[29] Carol I, Prat C, Lopez CM. Normal/Shear cracking model: Application to discrete crack analysis. J Eng Mech 1997; 123(8):765-73.

[30] Atkinson RH, Amadei BP, Saeb S, Sture S. Response of masonry bed joints in direct shear. J Struct Eng 1989; 115(9):2276-96.

[31] Niwa J, Maekawa K, Okamura H. Nonlinear finite element analysis of deep beam. IABSE Colloquium 1981, 34:625-38, Delft.

[32] Calderini C, Cattari S, Lagomarsino S. In-plane strength of unreinforced masonry piers. Earthq Eng Struct Dyn 2009; 38(2):243-67.

[33] Magenes G, Calvi GM. In-plane seismic response of brick masonry walls. Earthq Eng Struct Dyn 1997; 26(11):1091-112.

[34] Ganz HR, Thurlimann B. Tests on masonry walls under normal and shear loading. Report No. 7502-3, Inst Struct Eng, ETH Zurich; 1984 (in German).

[35] Abrams D, Shah N. Cyclic load testing of unreinforced masonry walls. Report No. 9226-10, Adv Constr Technol Cent, Newmark Civil Eng Lab, Dep Civil Eng, Univ Illinois Urbana-Champaign, USA; 1992. 
[36] Yaghoubifar A. Experimental and analytical investigation on the behavior of strengthened brick walls by steel bars and concrete, MSc. Dissertation, Dep Civil Eng, Tarbiat Modares Univ: Tehran; 2008. 


\section{List of figures}

Figure 1: Different failure modes of masonry.

Figure 2: Constitutive model for biaxial compression stress state.

Figure 3: Variation of compressive strength with $\theta$ for $\beta=-1$.

Figure 4: Variation of compressive strength with $\theta$ proposed by Ganz [23].

Figure 5: Simplified model for variation of uniaxial compressive strength with $\theta$.

Figure 6: Tensile cracking of masonry elements.

Figure 7: Tensile behavior of masonry element.

Figure 8: Constitutive model for tensile stress state (straight cracking).

Figure 9: Analysis of two masonry panels with different diagonal tension behavior.

Figure 10: Shear transfer model for a single crack .

Figure 11: Parametric study on the effects of $\alpha$ on friction angle $\varphi$.

Figure 12: Elasto-plastic model for contact compressive stress.

Figure 13: Variation of $\alpha$ with friction coefficient of masonry.

Figure 14: Softening rule in crack surface.

Figure 15: Total shear model for masonry.

Figure 16: Behavior of specimen with 7mm mortar thickness tested by Atkinson et al. [30].

Figure 17: Compressive strength reduction factor in biaxial compression-tension stress states.

Figure 18: The adopted failure criteria.

Figure 19: Failure criteria in $\sigma_{y}-\tau_{x y}$ space.

Figure 20: Applied in-plane stresses and corresponding strains in the element.

Figure 21: Analysis procedure flow chart for nonlinear analysis of masonry elements.

Figure 22: Adopted method for global behavior of Masonry walls.

Figure 23: Masonry wall division into fibers.

Figure 24: Moment-curvature analysis of the wall.

Figure 25: Moment and curvature distribution along the wall height.

Figure 26: Modeling masonry wall under shear stresses.

Figure 27: Geometry of the ETH Zurich shear walls tested by Ganz and Thurlimann [34].

Figure 28: Shear-displacement curves of the walls tested by Ganz and Thurlimann [34].

Figure 29: Geometry of the walls tested by Abrams and Shah [35].

Figure 30: Shear-displacement diagram of the walls tested by Abrams and Shah [35].

Figure 31: Shear-displacement diagram of the wall tested by Yaghoubifar [36].

\section{List of tables}

Table 1:Properties of specimen tested by Atkinson et al. [30].

Table 2:Elastic properties of ETH Zurich walls.

Table 3:Inelastic properties of ETH Zurich walls.

Table 4:Properties of Abrams and Shah shear walls [35].

Table 5:Material properties of the tests performed by Yaghoubifar [36]. 


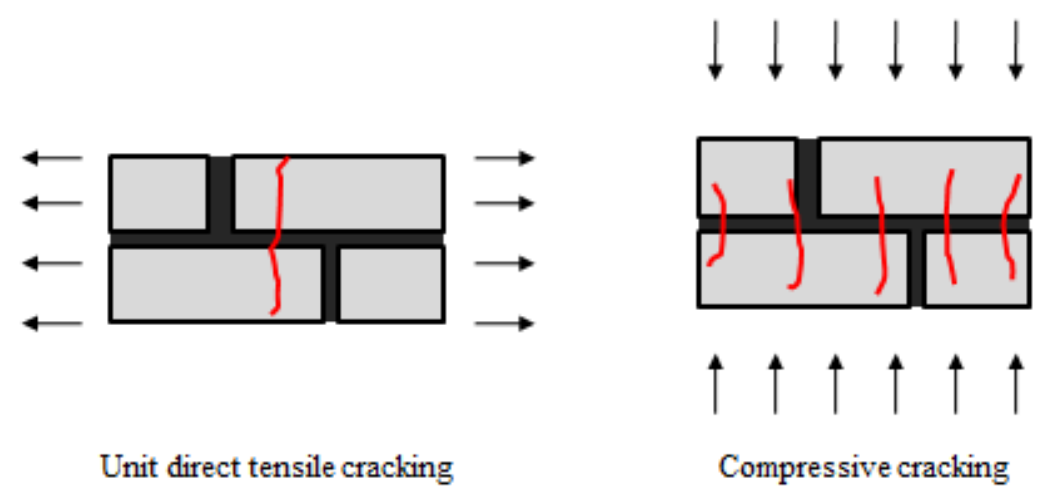

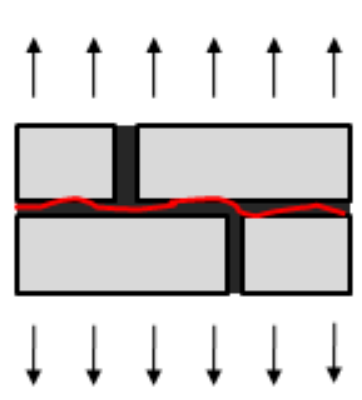

Joint tensile cracking

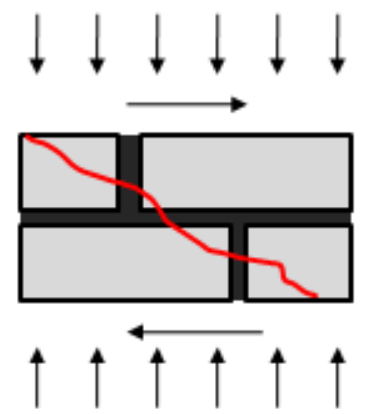

Diagonal tension cracking (straight cracking)

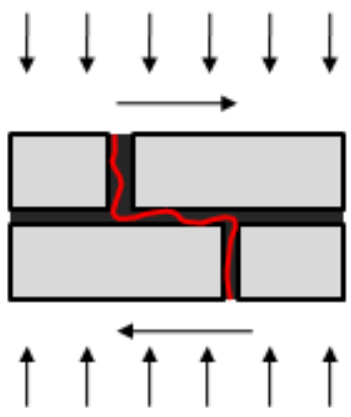

Diagonal tension cracking (stepped cracking)

Figure 1: Different failure modes of masonry.

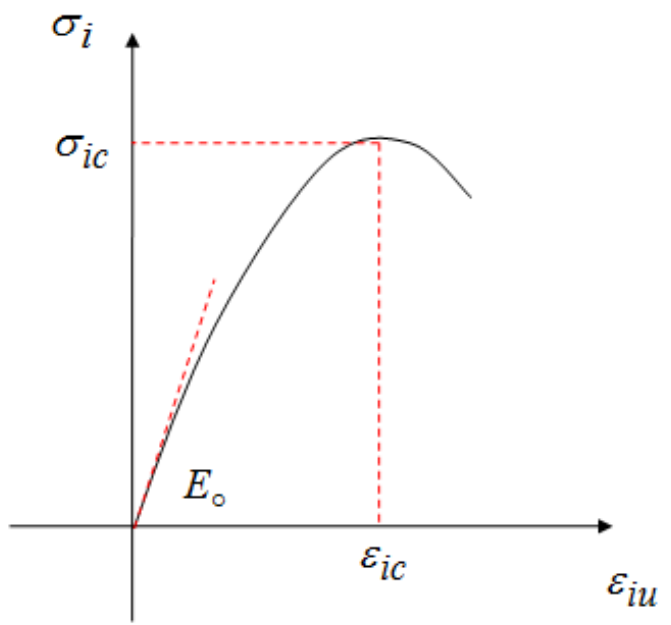

Figure 2: Constitutive model for biaxial compression stress state. 

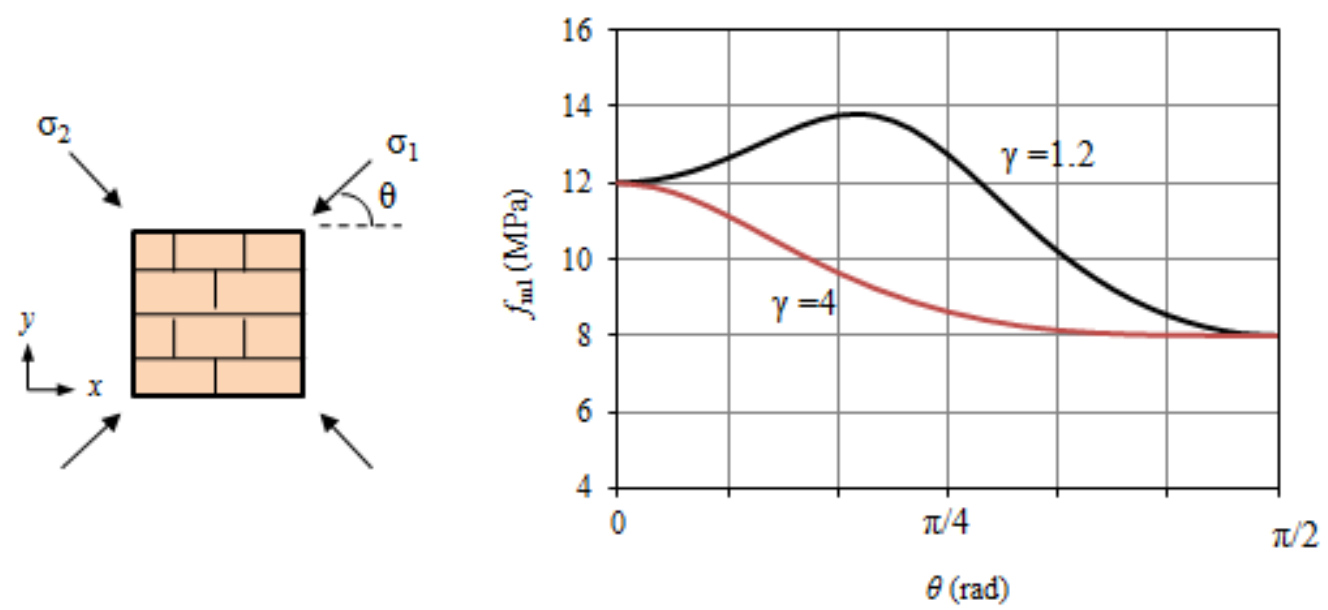

Figure 3: Variation of compressive strength with $\theta$ for $\beta=-1$.
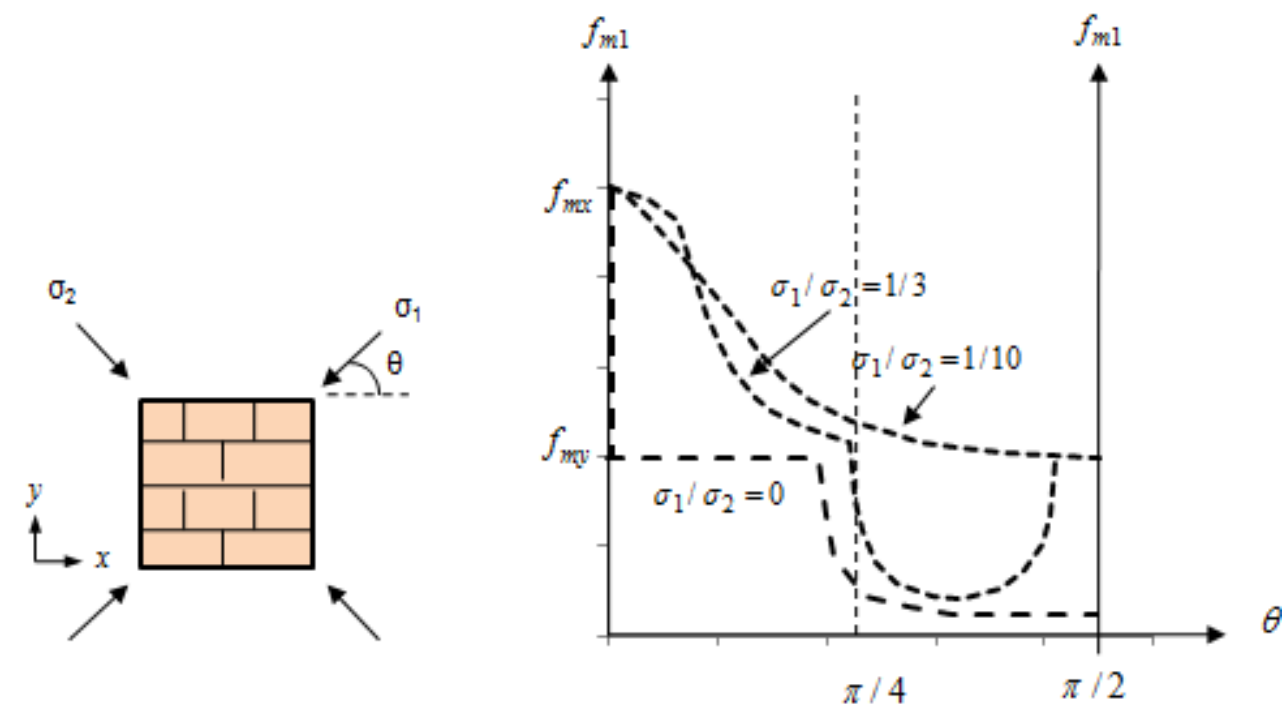

Figure 4: Variation of compressive strength with $\theta$ proposed by Ganz [23].

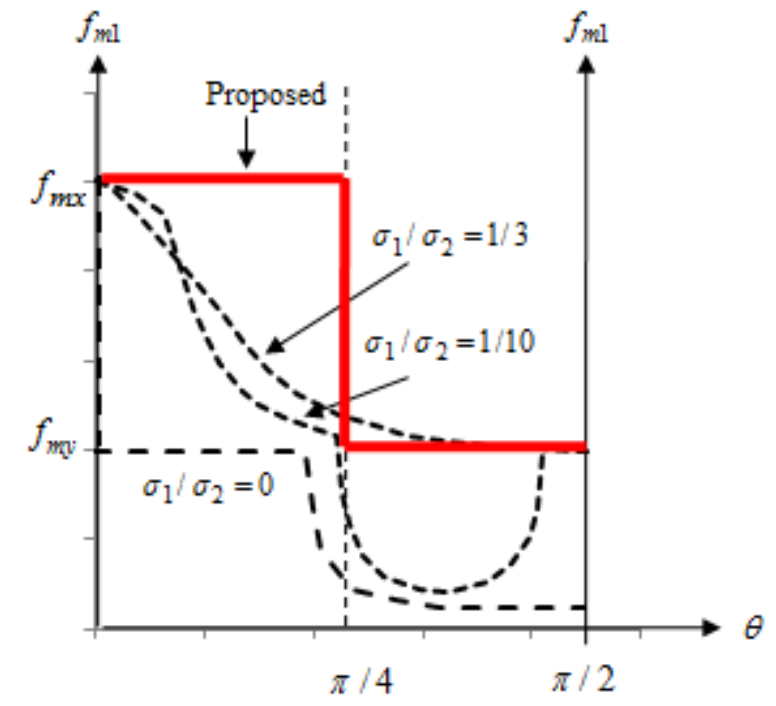

Figure 5: Simplified model for variation of uniaxial compressive strength with $\theta$. 


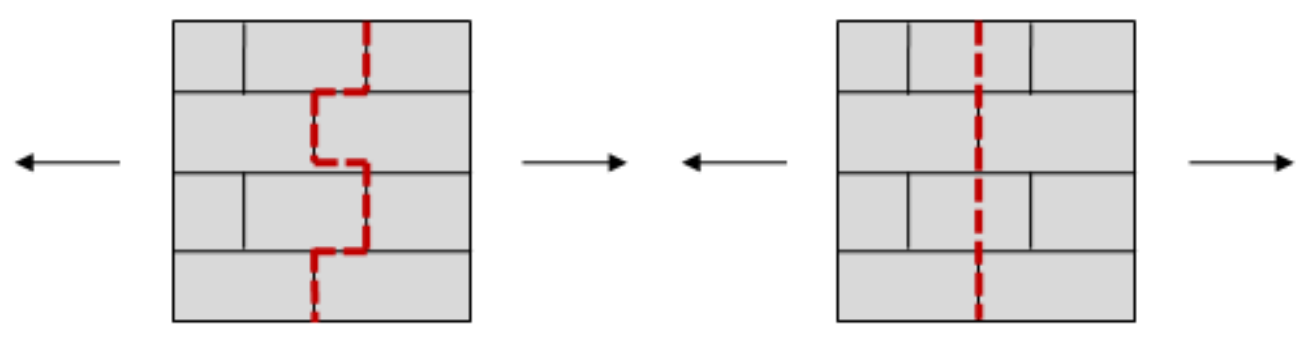

Figure 6: Tensile cracking of masonry elements.

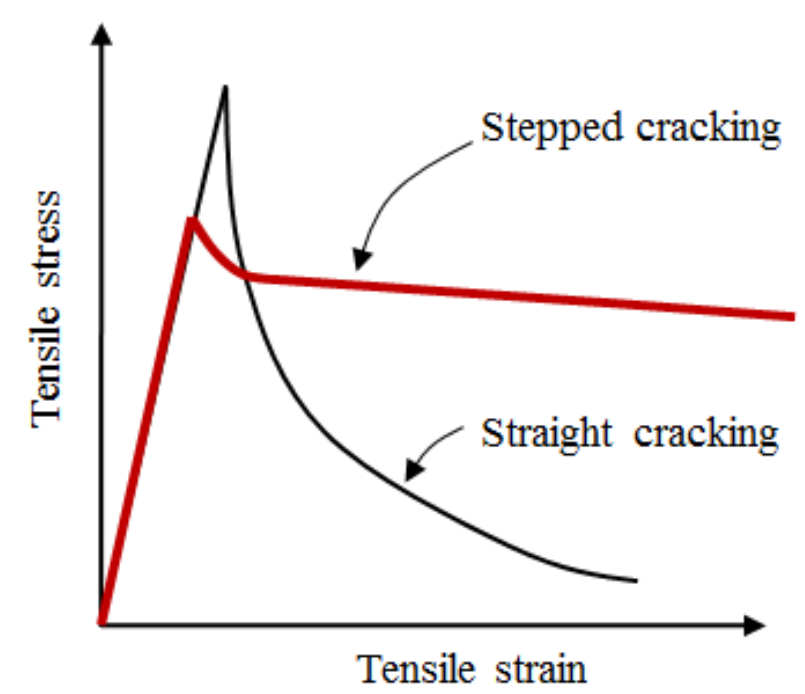

Figure 7: Tensile behavior of masonry element.

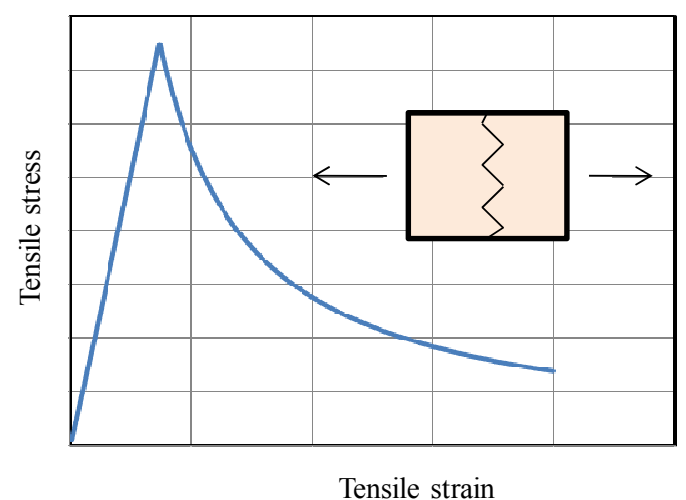

Figure 8: Constitutive model for tensile stress state (straight cracking). 

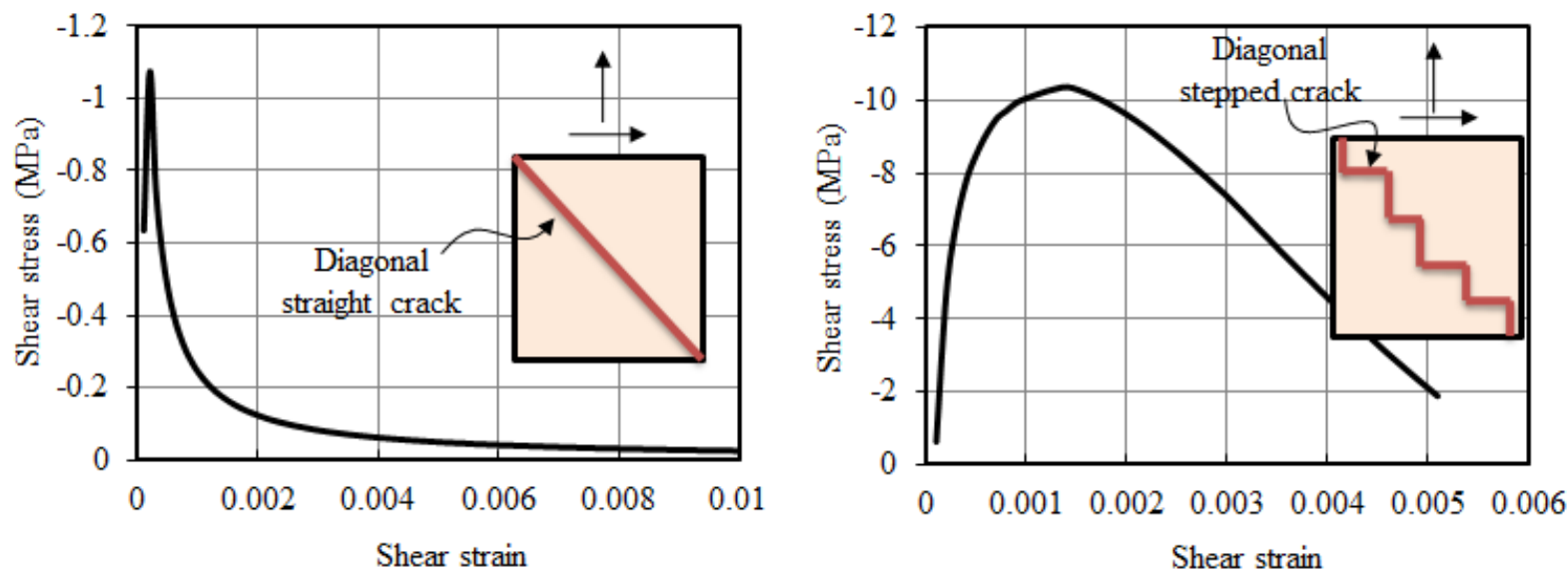

Figure 9: Analysis of two masonry panels with different diagonal tension behavior.

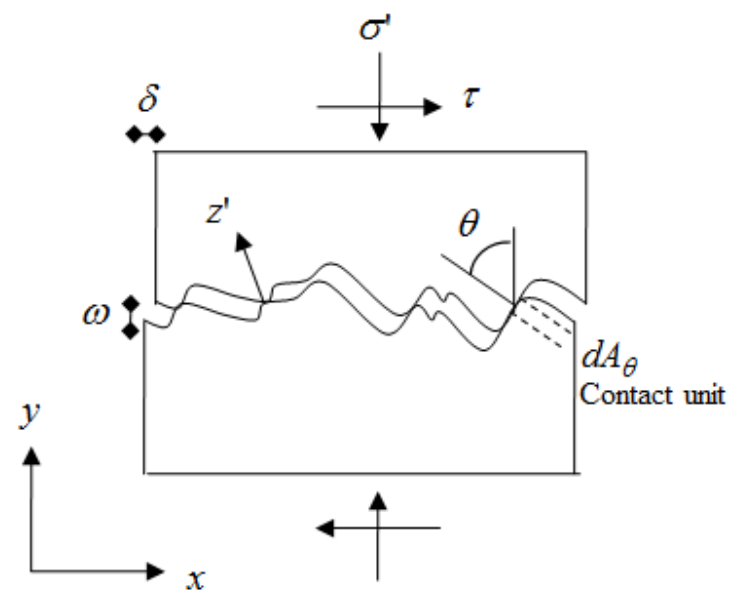

Figure 10: Shear transfer model for a single crack.

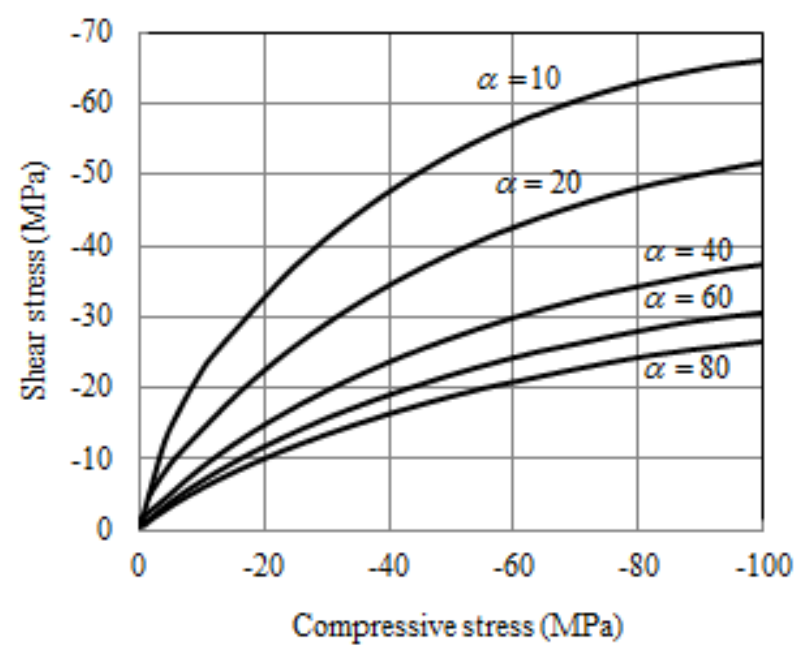

Figure 11: Parametric study on the effects of $\alpha$ on friction angle $\varphi$. 


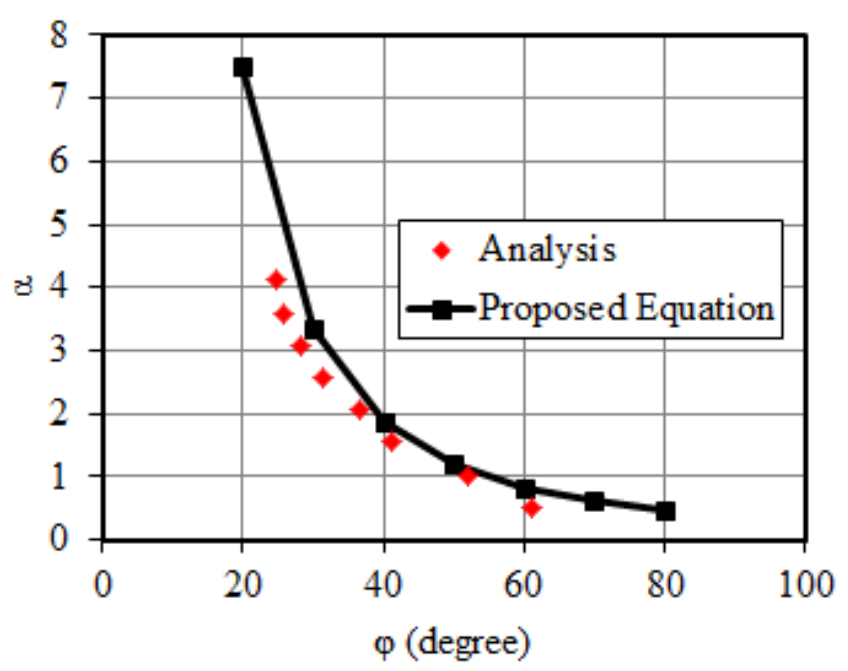

Figure 12: Variation of $\alpha$ with friction coefficient of masonry.

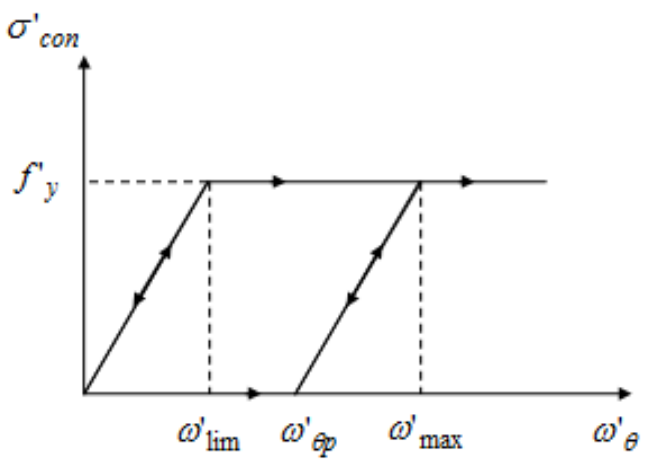

Figure 13: Elasto-plastic model for contact compressive stress.

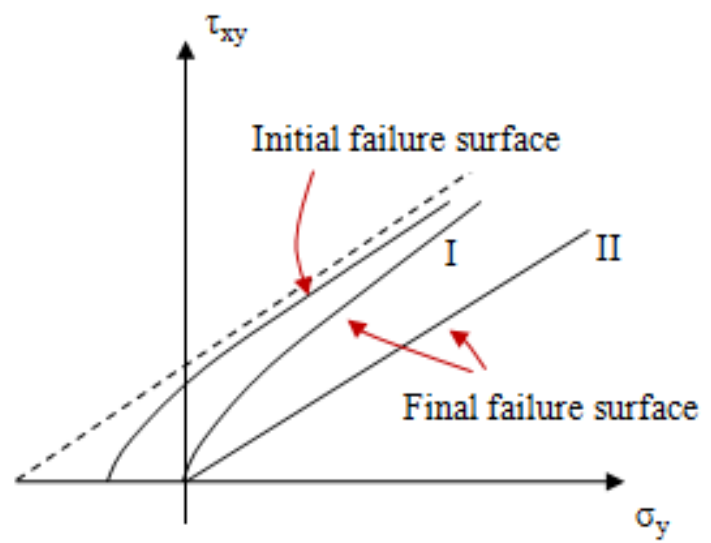

Figure 14: Softening rule in crack surface. 


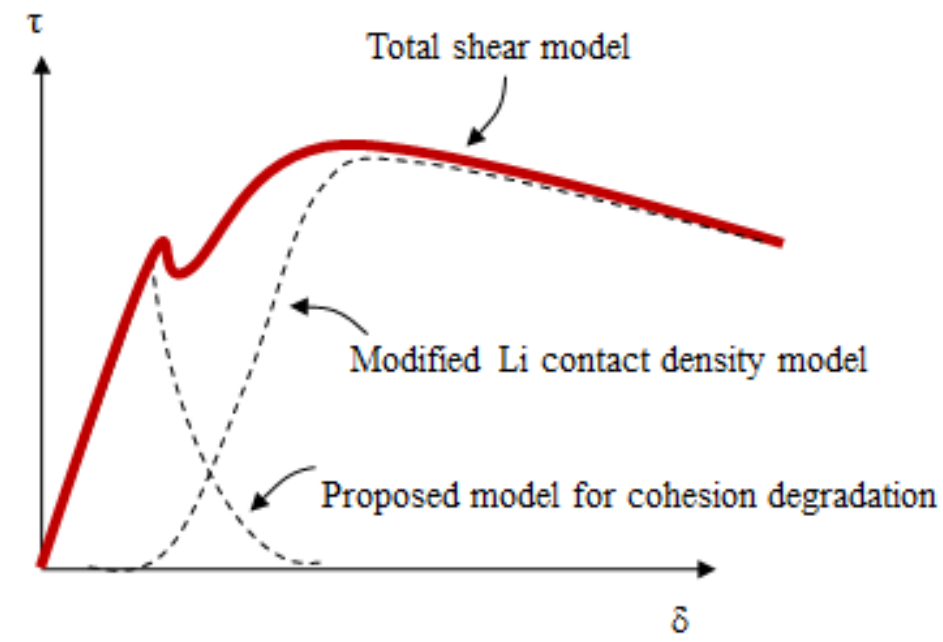

Figure 15: Total shear model for masonry.

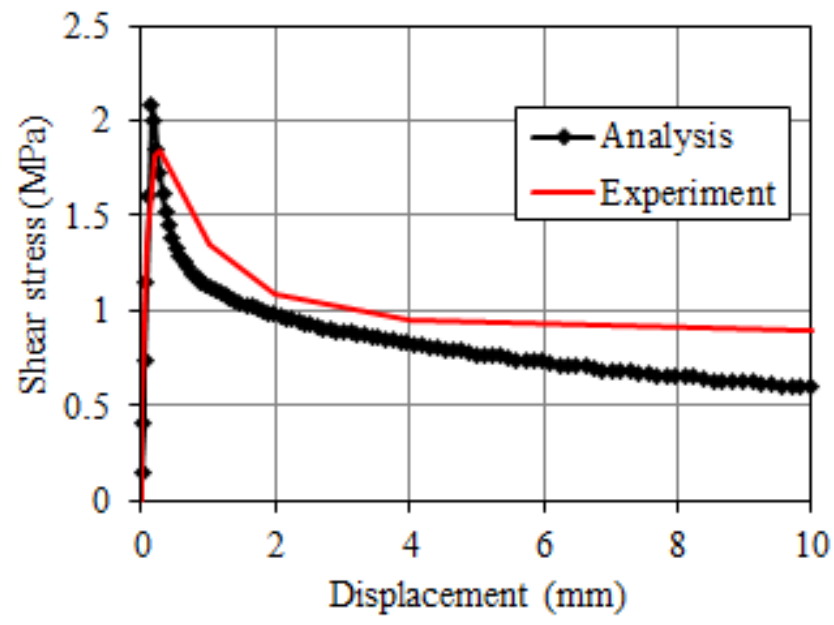

Figure 16: Behavior of specimen with 7mm mortar thickness tested by Atkinson et al. [30].

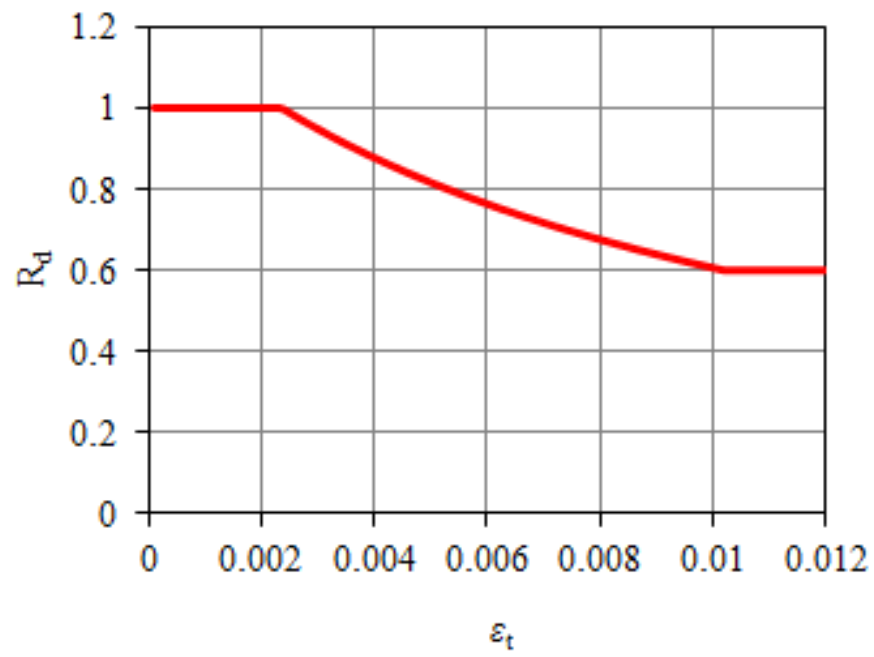

Figure 17: Compressive strength reduction factor in biaxial compression-tension stress states. 


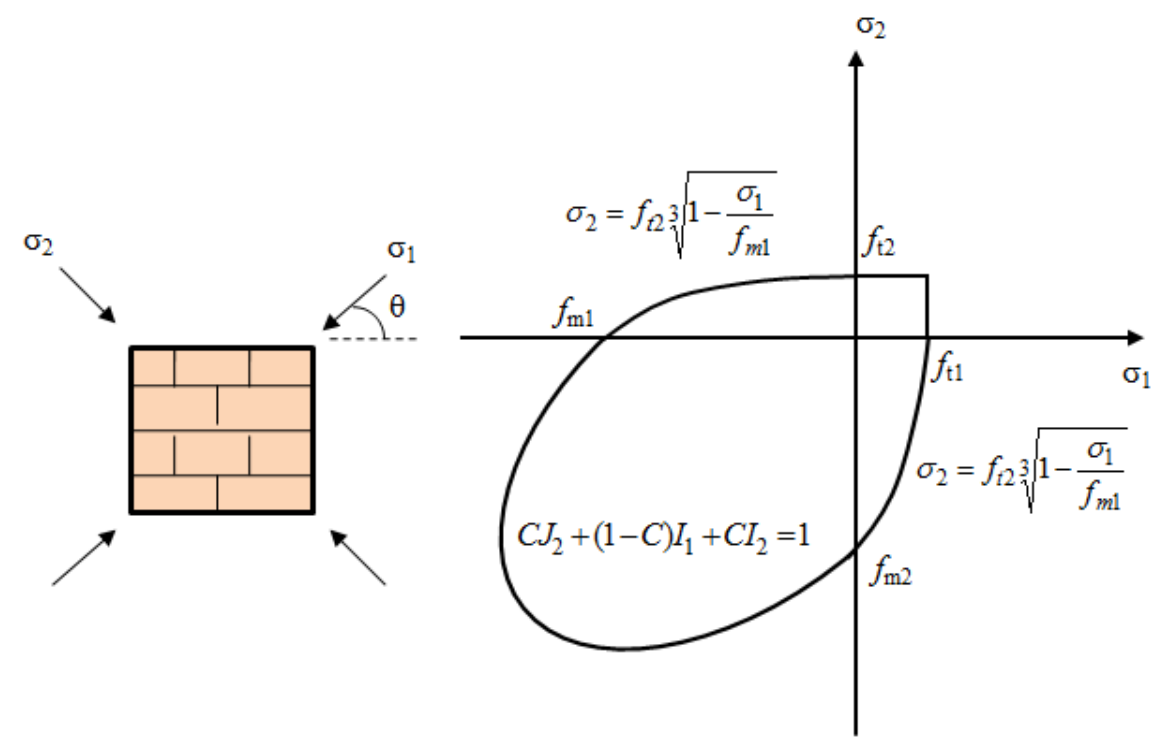

Figure 18: The adopted failure criteria.
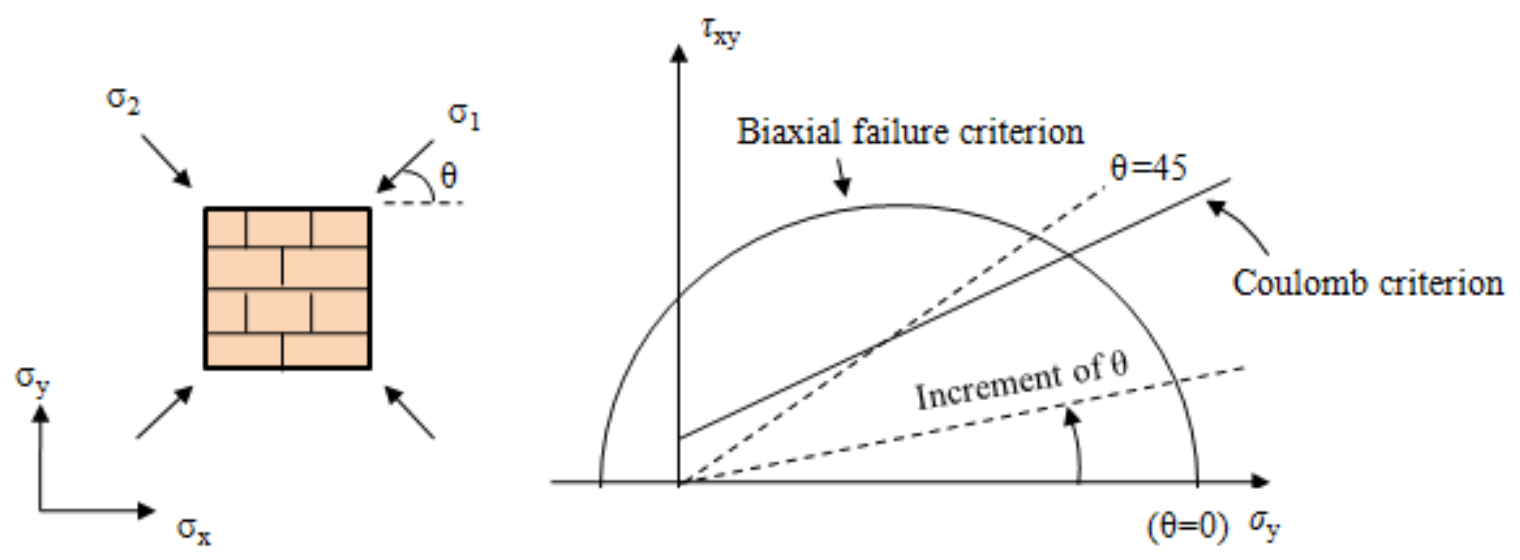

Figure 19: Failure criteria in $\sigma_{y}-\tau_{x y}$ space.

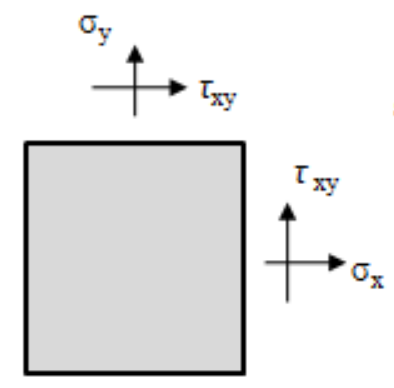

Stresses

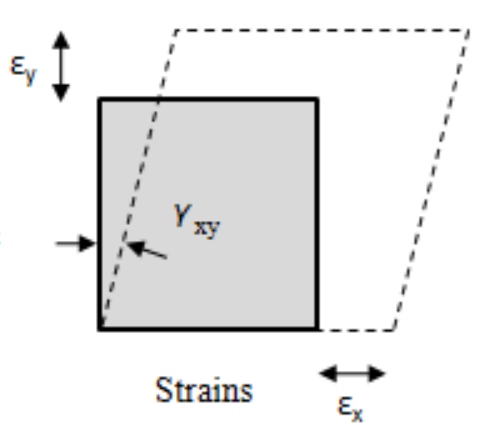

Figure 20: Applied in-plane stresses and corresponding strains in the element. 


\section{Input: Material properties, loading conditions}

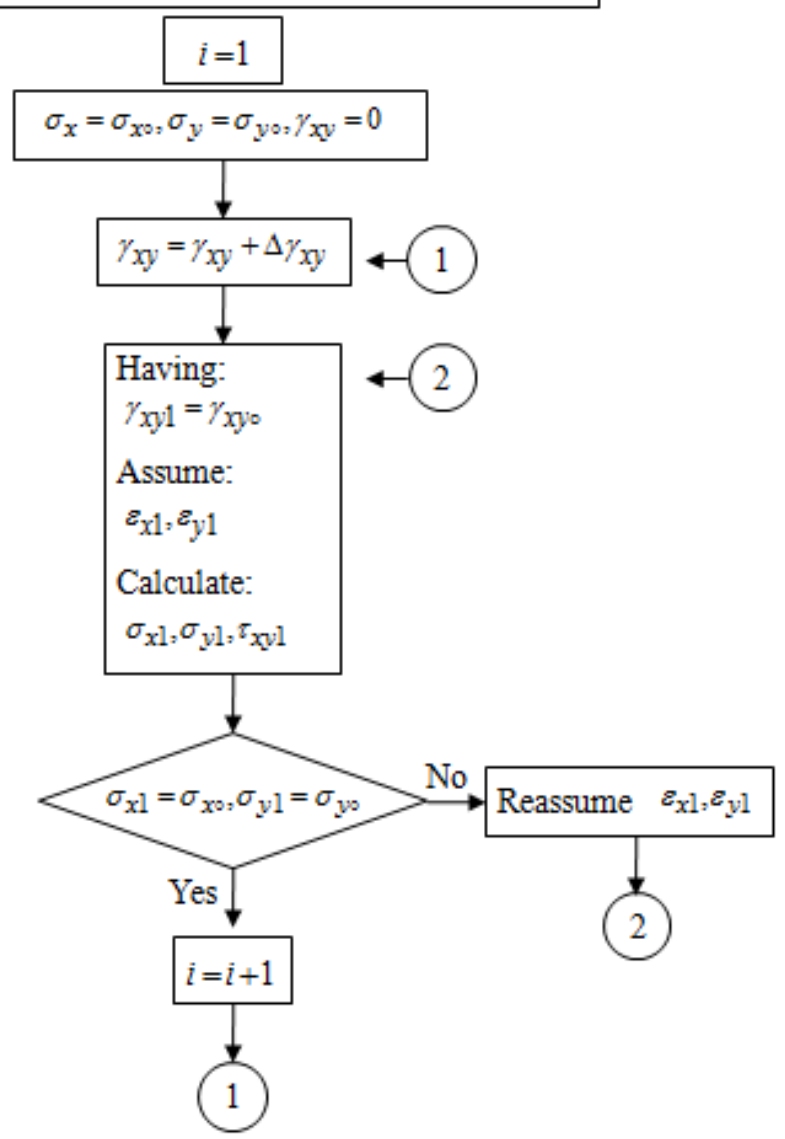

Figure 21: Analysis procedure flow chart for nonlinear analysis of masonry elements. 

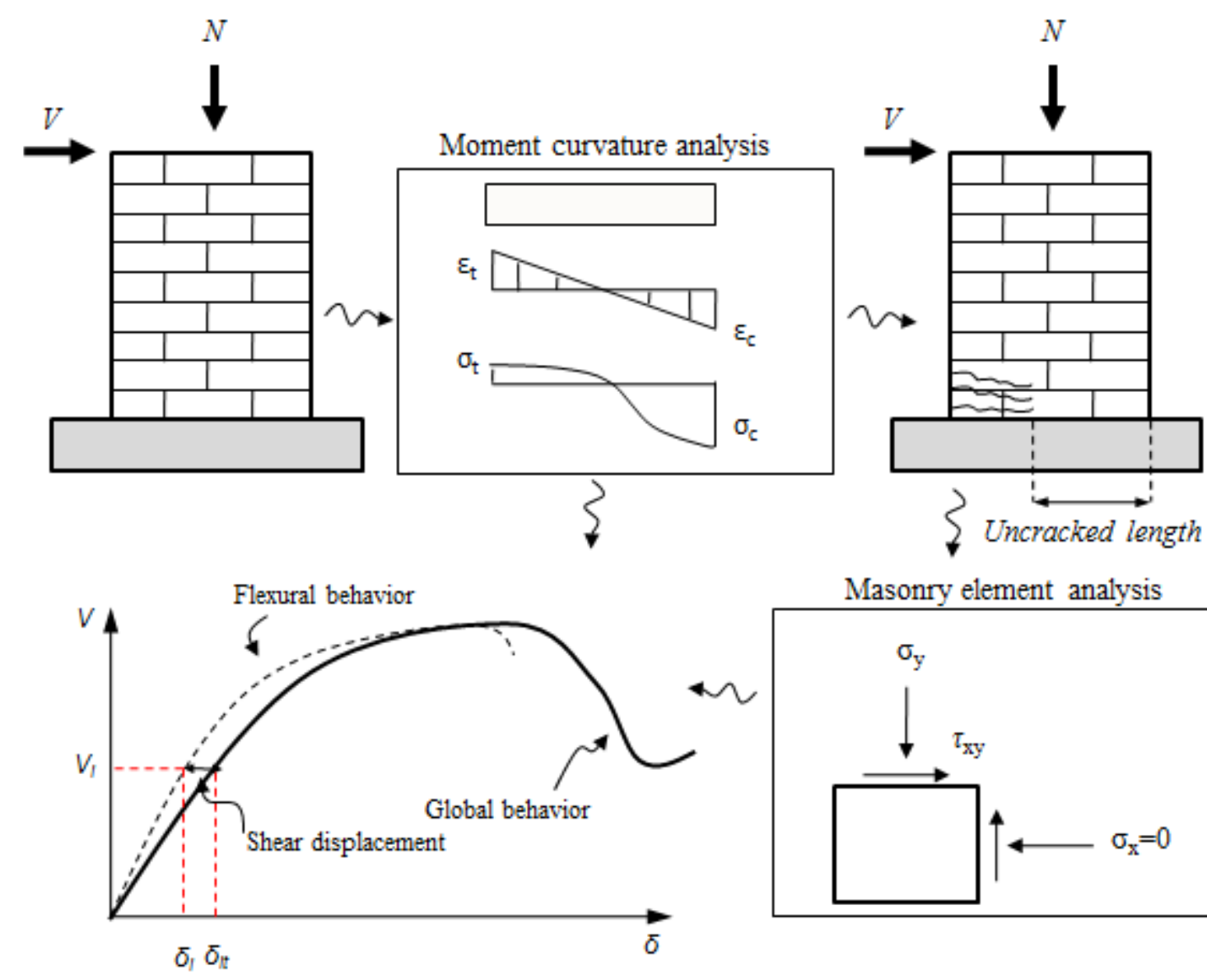

Masonry element analysis

Figure 22: Adopted method for global behavior of Masonry walls.

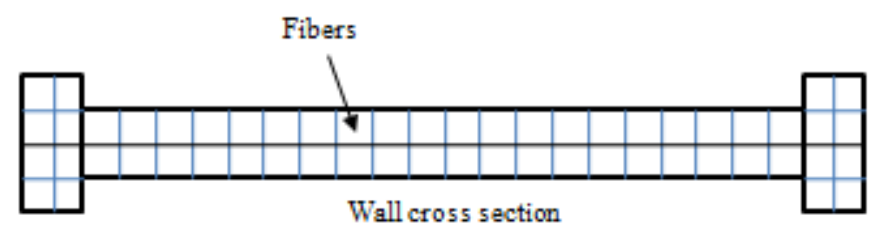

Figure 23: Masonry wall division into fibers.
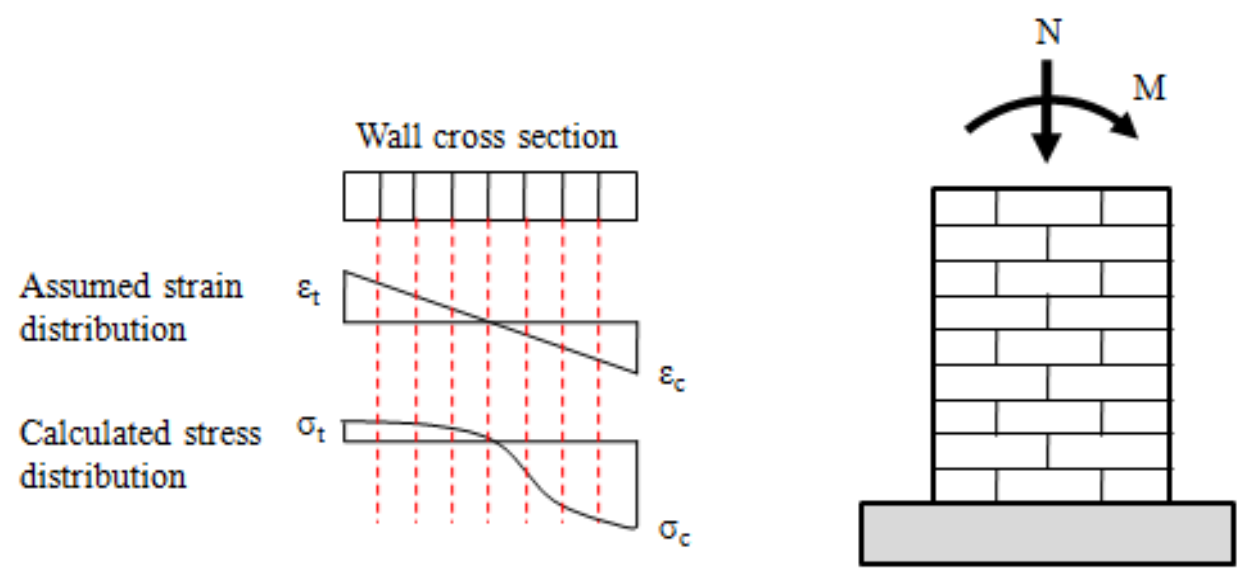

Figure 24: Moment-curvature analysis of the wall. 


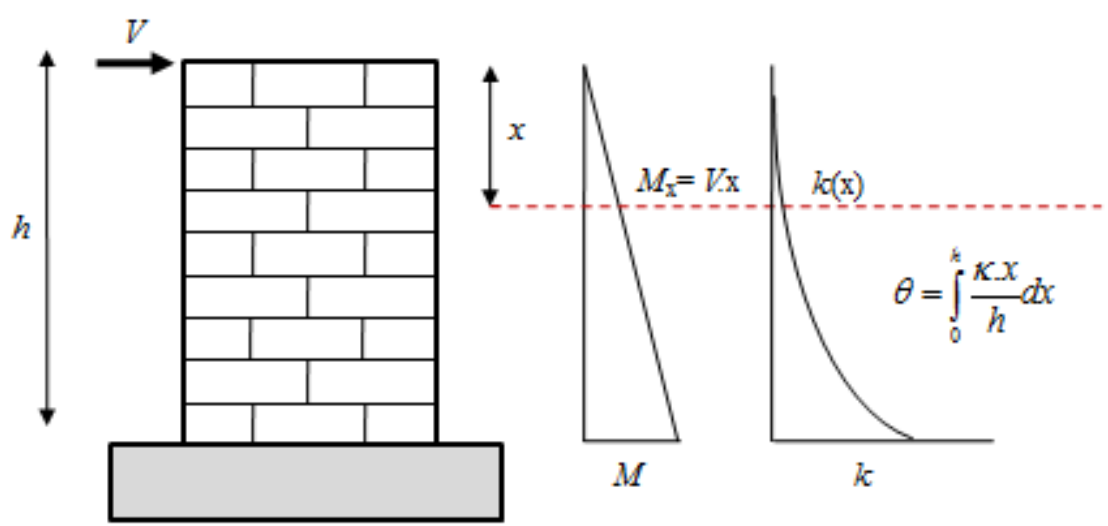

Figure 25: Moment and curvature distribution along the wall height.

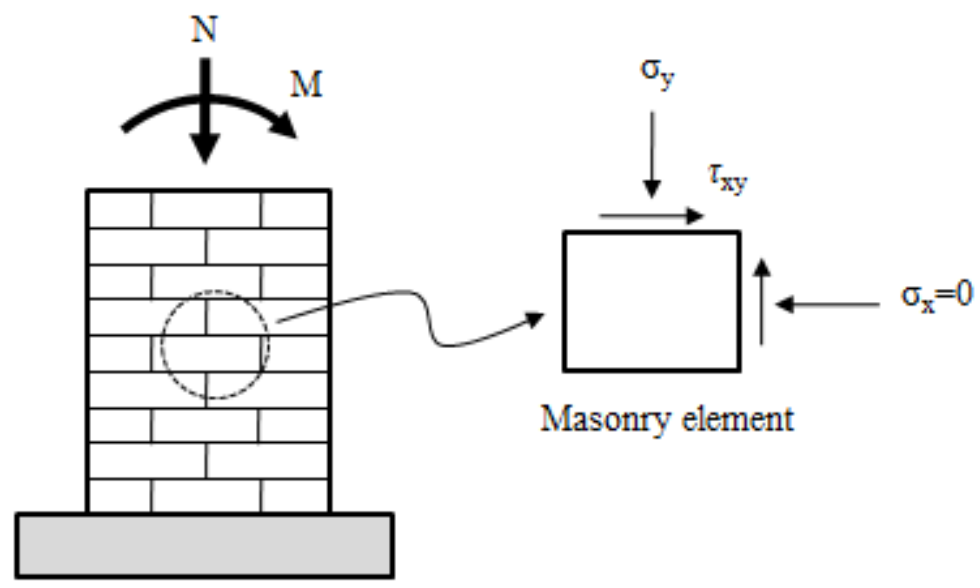

Figure 26: Modeling masonry wall under shear stresses. 


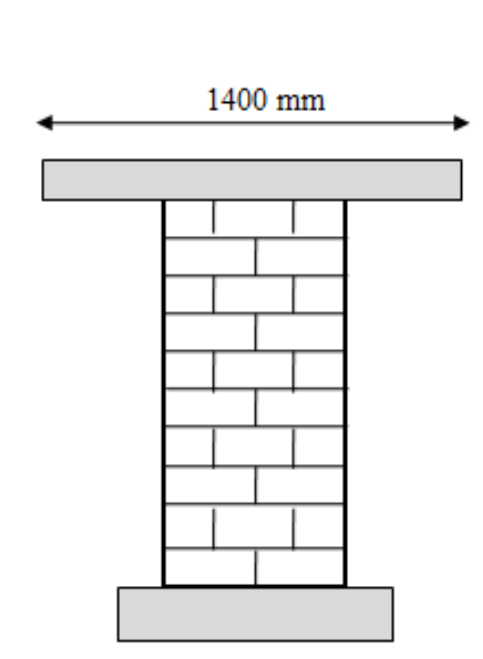

Section $B$

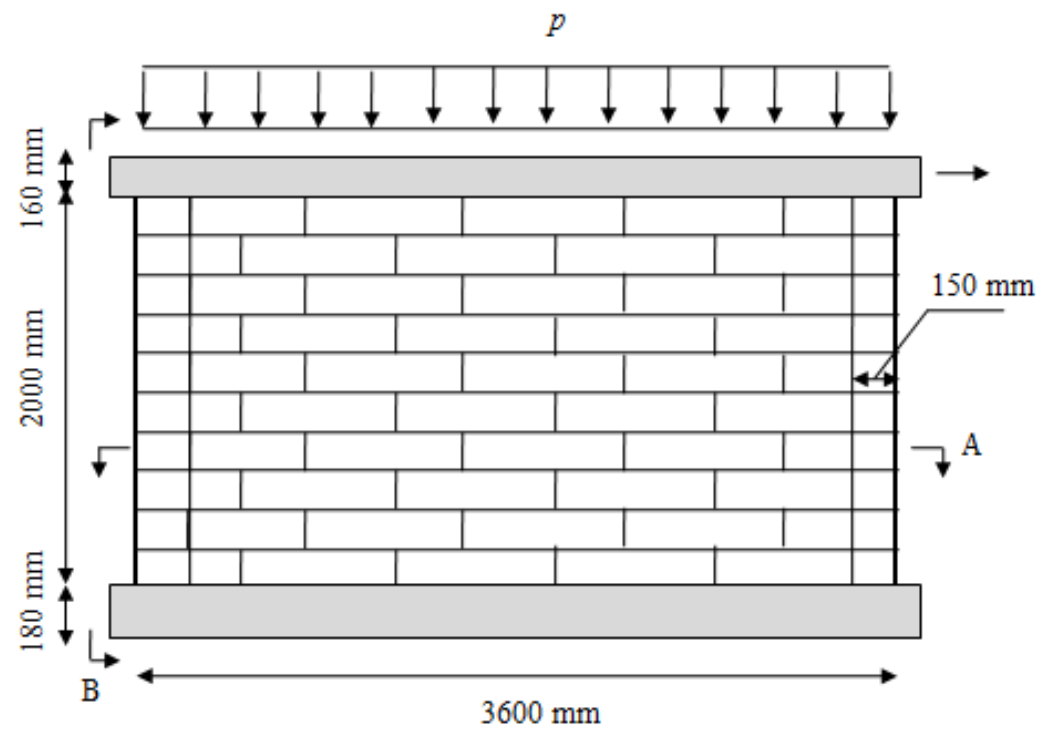

$$
\text { 寻 }
$$

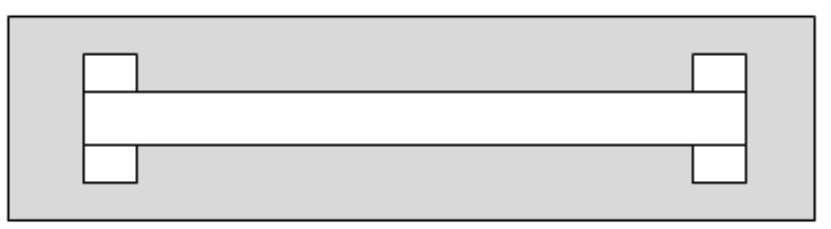

Section $A$

Figure 27: Geometry of the ETH Zurich shear walls tested by Ganz and Thurlimann [34].
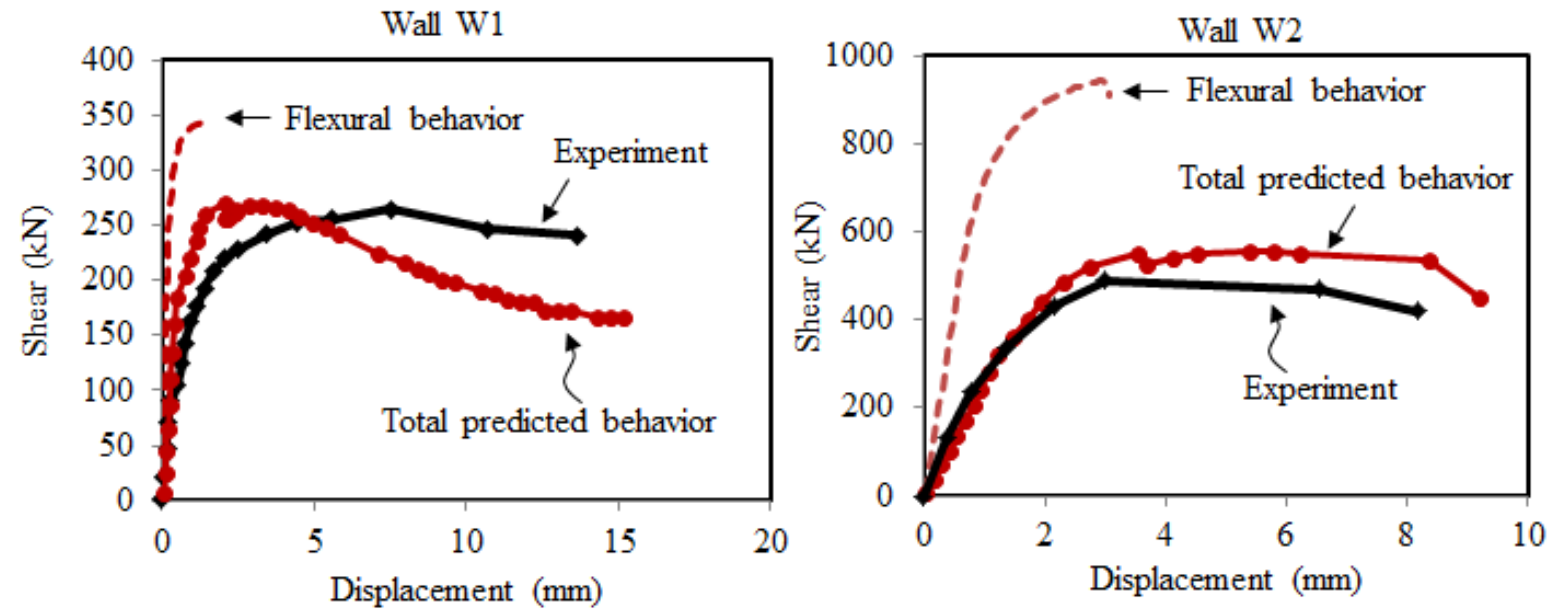

Figure 28: Shear-displacement curves of the walls tested by Ganz and Thurlimann [34]. 


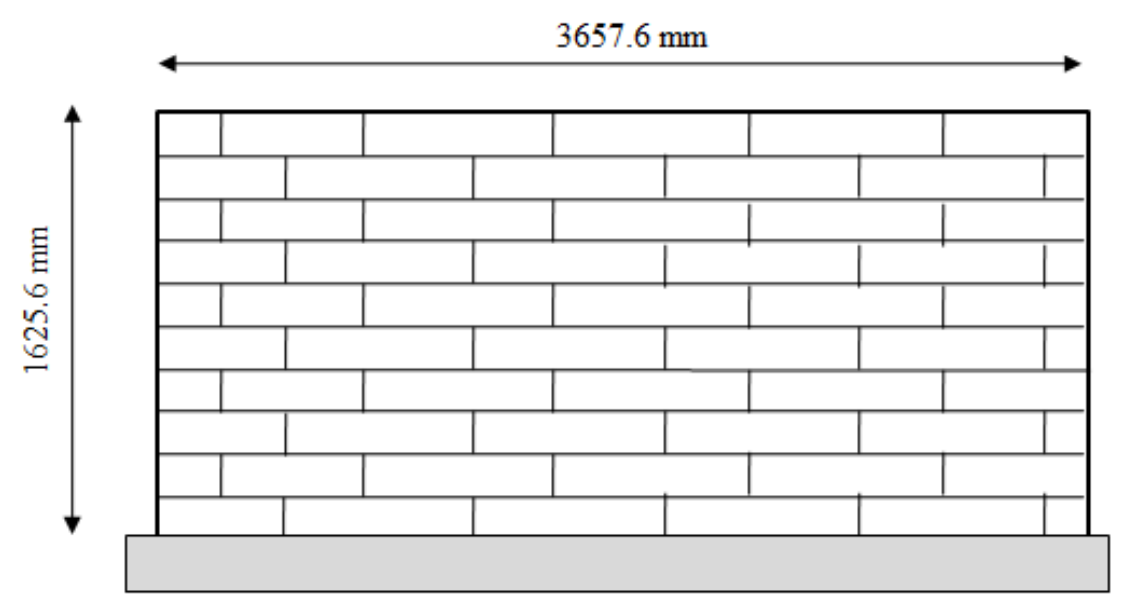

Wall W1

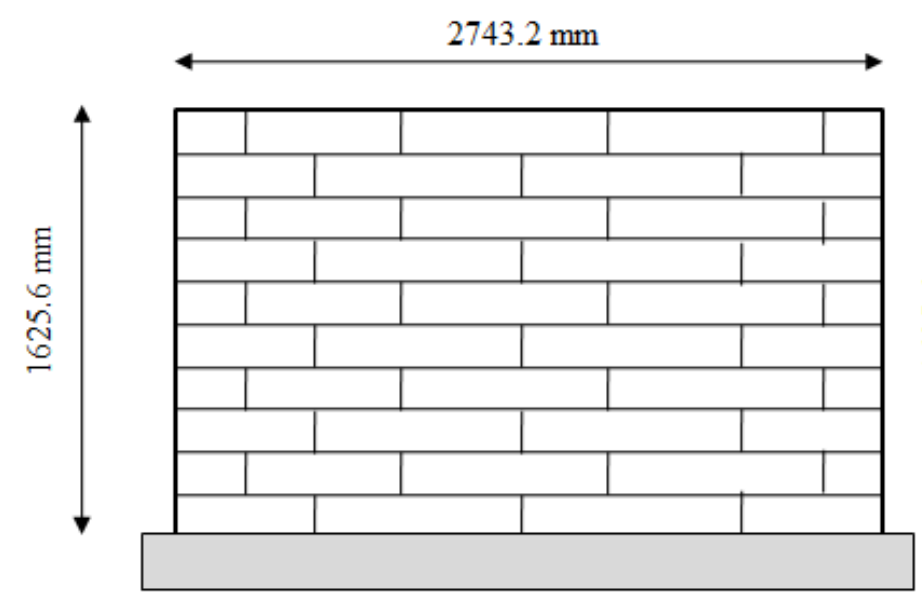

Wall W2

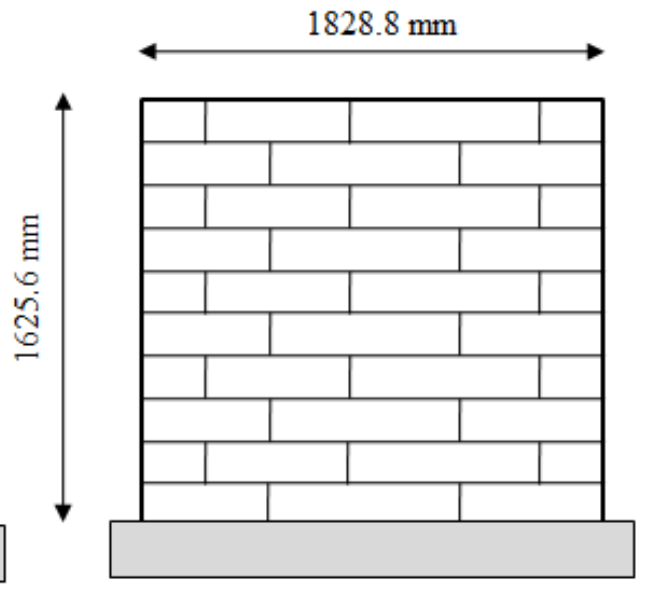

Wall W3

Figure 29: Geometry of the walls tested by Abrams and Shah [35]. 
Wall W1

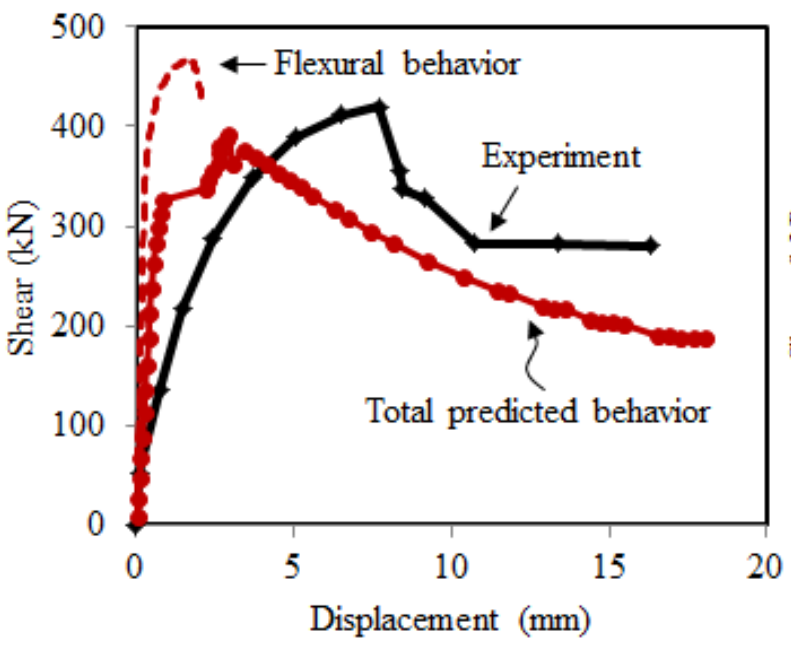

Wall W2

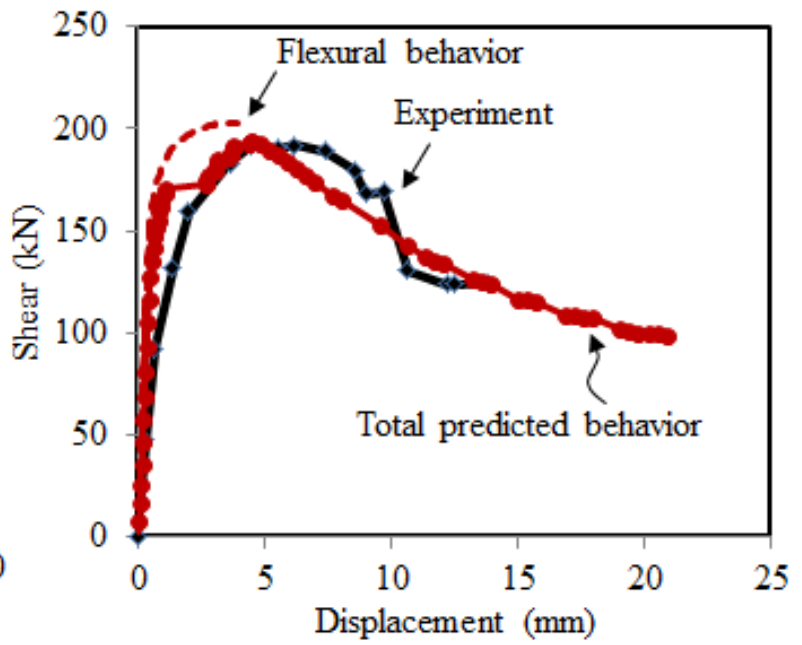

Wall W3

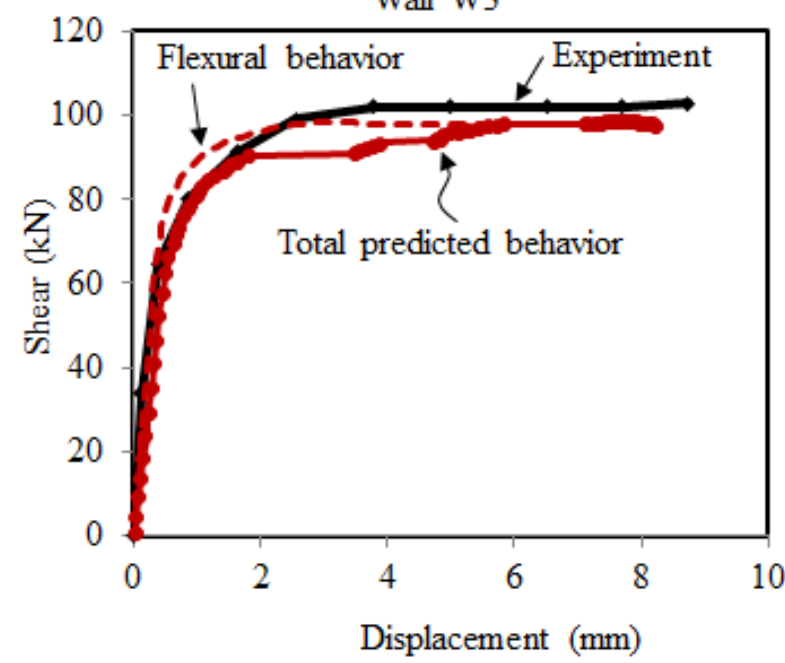

Figure 30: Shear-displacement diagram of the walls tested by Abrams and Shah [35].

Total gravity load $=40 \mathrm{KN}$
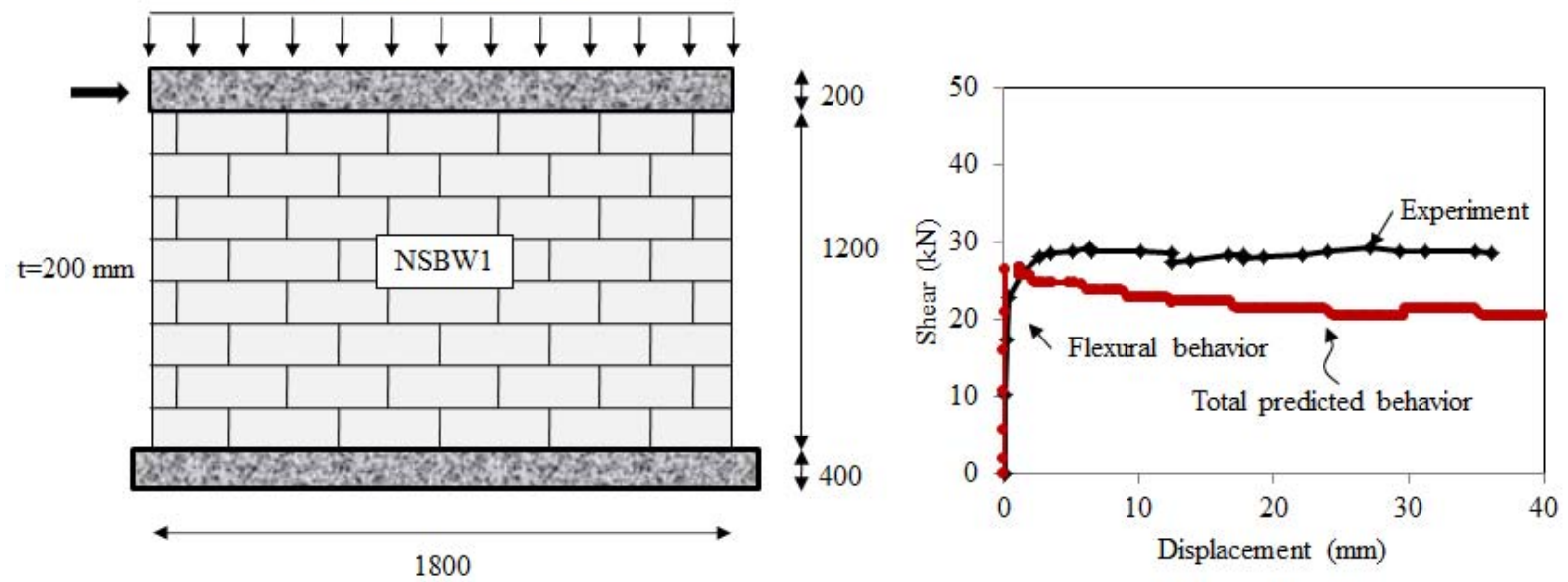

Figure 31: Shear-displacement diagram of the wall tested by Yaghoubifar [36]. 
Table 1: Properties of specimen tested by Atkinson et al. [30].

\begin{tabular}{|c|c|c|c|c|c|}
\hline \multirow{2}{*}{ Unit } & \multirow{2}{*}{ Mortar } & \multicolumn{2}{|c|}{ Peak Values } & \multicolumn{2}{c|}{ Residual Values } \\
\cline { 3 - 6 } & & $\begin{array}{c}\mathrm{C} \\
(\mathrm{MPa})\end{array}$ & $\tan \varphi$ & $\begin{array}{c}\mathrm{C} \\
(\mathrm{MPa})\end{array}$ & $\tan \varphi$ \\
\hline Old Clay Units (7mm) & $1: 2: 9$ & 0.213 & 0.64 & 0.038 & 0.693 \\
\hline Axial Load & 49 & $\mathrm{KN}$ & & & \\
\end{tabular}

Table 2: Elastic properties of ETH Zurich walls.

\begin{tabular}{|c|c|c|c|}
\hline $\begin{array}{c}E_{x} \\
(\mathrm{MPa})\end{array}$ & $\begin{array}{c}E_{y} \\
(\mathrm{MPa})\end{array}$ & $\begin{array}{c}v_{x y} \\
(\mathrm{MPa})\end{array}$ & $\begin{array}{c}G_{x y} \\
(\mathrm{MPa})\end{array}$ \\
\hline 2460 & 5460 & 0.18 & 1130 \\
\hline
\end{tabular}

Table 3: Inelastic properties of ETH Zurich walls.

\begin{tabular}{|c|c|c|c|c|c|}
\hline $\begin{array}{c}f_{t x} \\
(\mathrm{MPa})\end{array}$ & $\begin{array}{c}f_{t y} \\
(\mathrm{MPa})\end{array}$ & $\begin{array}{c}f_{m x} \\
(\mathrm{MPa})\end{array}$ & $\begin{array}{c}f_{m y} \\
(\mathrm{MPa})\end{array}$ & $\begin{array}{c}c \\
(\mathrm{MPa})\end{array}$ & $\begin{array}{c}\varphi \\
\left(^{\circ}\right.\end{array}$ \\
\hline 0.28 & 0.05 & 1.87 & 7.61 & 0.2 & 36 \\
\hline
\end{tabular}

Table 4: Properties of Abrams and Shah [35] shear walls.

\begin{tabular}{|c|c|c|c|c|c|c|c|c|c|c|c|}
\hline Specimen & $\begin{array}{c}\text { Length } \\
(\mathrm{mm})\end{array}$ & $\begin{array}{c}\text { Height } \\
(\mathrm{mm})\end{array}$ & $\begin{array}{c}\text { Thicknes } \\
(\mathrm{mm})\end{array}$ & $\begin{array}{c}f_{t x} \\
(\mathrm{MPa})\end{array}$ & $\begin{array}{c}f_{t y} \\
(\mathrm{MPa})\end{array}$ & $\begin{array}{c}f_{m x} \\
(\mathrm{MPa})\end{array}$ & $\begin{array}{c}f_{m y} \\
(\mathrm{MPa})\end{array}$ & $\begin{array}{c}c \\
(\mathrm{MPa})\end{array}$ & $\begin{array}{c}\varphi \\
\left({ }^{\circ}\right)\end{array}$ & $\begin{array}{c}\text { Vertical } \\
\text { stress } \\
(\mathrm{MPa})\end{array}$ & Failure mode \\
\hline $\mathrm{W} 1$ & 3567.6 & 1625.6 & 198 & 0.45 & 0.15 & 2.2 & 6.4 & 0.7 & 26.57 & 0.527 & Diagonal shear cracking \\
\hline $\mathrm{W} 2$ & 2743.2 & 1625.6 & 198 & 0.45 & 0.15 & 2.2 & 6.4 & 0.7 & 26.57 & 0.527 & Flexural cracking/toe crushing \\
\hline $\mathrm{W} 3$ & 1828.8 & 1625.6 & 198 & 0.45 & 0.15 & 2.2 & 6.4 & 0.7 & 26.57 & 0.527 & Rocking \\
\hline
\end{tabular}

Table 5: Material properties of the tests performed by Yaghoubifar [36].

\begin{tabular}{|c|c|c|c|c|c|}
\hline $\begin{array}{c}f_{t x} \\
(\mathrm{MPa})\end{array}$ & $\begin{array}{c}f_{t y} \\
(\mathrm{MPa})\end{array}$ & $\begin{array}{c}f_{m x} \\
(\mathrm{MPa})\end{array}$ & $\begin{array}{c}f_{m y} \\
(\mathrm{MPa})\end{array}$ & $\begin{array}{c}\mathrm{C} \\
(\mathrm{MPa})\end{array}$ & $\begin{array}{c}\varphi \\
\left.{ }^{\circ}\right)\end{array}$ \\
\hline 0.2 & 0.05 & 2 & 5.7 & 0.1 & 28 \\
\hline
\end{tabular}

